\title{
A novel role of NLRP3-generated IL-1 $\beta$ in the acute-chronic transition of peripheral lipopolysaccharide-elicited neuroinflammation: implications for sepsis- associated neurodegeneration
}

Zhan Zhao ${ }^{1,2,3 \dagger}$, Yubao Wang ${ }^{2,3^{*}+}$, Ran Zhou ${ }^{1,2}$, Yi Li$^{2}$, Yun Gao ${ }^{2}$, Dezhen $\mathrm{Tu}^{2}$, Belinda Wilson ${ }^{2}$, Sheng Song ${ }^{2}$, Jing Feng ${ }^{1,2^{*}}$, Jau-Shyong Hong ${ }^{2}$ and Jerrel L. Yakel ${ }^{2}$

\begin{abstract}
Background: Sepsis-associated acute brain inflammation, if unresolved, may cause chronic neuroinflammation and resultant neurodegenerative diseases. However, little is known how the transition from acute to chronic neuroinflammation, which is critical for the following progressive neurodegeneration, occurs in sepsis. The goal of this study was to investigate potential immune factors regulating the transition process using a widely used endotoxemia LPS mouse model. This model shows distinct acute and chronic phases of neuroinflammation and recapitulates many cardinal features of Parkinson's disease, thus, providing a unique opportunity for studying phase transition of neuroinflammation.

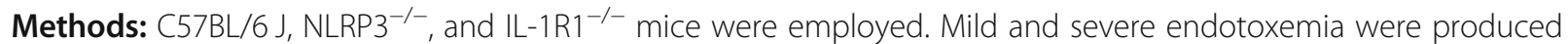
by LPS ip injection at 1 or $5 \mathrm{mg} / \mathrm{kg}$. Neuroinflammation in vitro and in vivo was assessed with proinflammatory cytokine expression by qPCR or ELISA and microglial activation by immunohistochemical analysis.

Neurodegeneration was measured by manual and stereological counts of nigral dopaminergic neurons and immunohistochemical analysis of protein nitrosylation and a-synuclein phosphorylation.

Results: LPS-elicited initial increases in mouse brain mRNA levels of TNFa, LL-6, LL-1 $\beta$, and MCP-1, and nigral microglial activation were not dose-related. By contrast, the delayed increase in brain mature IL-1 $\beta$ levels was dependent on LPS doses and protracted nigral microglial activation was only observed in high dose of LPS-treated mice. LPS-elicited increase in brain mature IL-1 $\beta$ but not IL-1a level was NLRP3-dependent. After high dose LPS treatment, deficiency of NLRP3 or IL-1R1 did not prevent the initiation of acute neuroinflammation but abolished chronic neuroinflammation. Genetic or pharmacological inhibition of the NLRP3-IL-1 $\beta$ axis repressed LPS-stimulated upregulation of chronic neuroinflammatory mediators including MHC-II, NOX2, and Mac1, and protected dopaminergic neurons. Ten months after LPS-elicited severe endotoxemia, nigral persisted microglial activation, elevated nitrosylated proteins and phosphorylated a-synuclein, and significant neuronal degeneration developed in wild-type mice but not in $\mathrm{NLRP3}^{-/-}$or $\mathrm{IL}-1 \mathrm{R}^{-/-}$mice.

(Continued on next page)
\end{abstract}

\footnotetext{
*Correspondence: yubaowang2020@hotmail.com; zyyhxkfj@126.com

'Zhan Zhao and Yubao Wang contributed equally to this work.

${ }^{2}$ Neurobiology Laboratory, National Institute of Environmental Health

Sciences, National Institutes of Health, Research Triangle Park, NC 27709, USA

${ }^{1}$ Respiratory Department, Tianjin Medical University General Hospital, Tianjin

300052, China

Full list of author information is available at the end of the article
}

C The Author(s). 2020 Open Access This article is distributed under the terms of the Creative Commons Attribution 4.0 International License (http://creativecommons.org/licenses/by/4.0/), which permits unrestricted use, distribution, and

reproduction in any medium, provided you give appropriate credit to the original author(s) and the source, provide a link to the Creative Commons license, and indicate if changes were made. The Creative Commons Public Domain Dedication waiver (http://creativecommons.org/publicdomain/zero/1.0/) applies to the data made available in this article, unless otherwise stated. 
(Continued from previous page)

Conclusions: This study uncovers a novel role of the NLRP3-IL-1 $\beta$ signaling pathway in gauging the severity of sepsisassociated inflammation and determining whether acute neuroinflammation will resolve or transition to low grade chronic neuroinflammation. These findings also provide novel targets for developing therapy for severe systemic infection-related neurodegeneration.

Keywords: Sepsis, Neuroinflammation, Acute-chronic transition, Neurodegeneration, NLRP3 inflammasome, IL-1ß, IL-1R1, Parkinson's disease

\section{Background}

Epidemiological investigations revealed that infections, such as sepsis (severe systemic infections) or viral infections, increase the risk of long-term brain dysfunction [1] and chronic neurodegeneration, including Parkinson's disease (PD), Alzheimer's disease (AD), and multiple sclerosis [2-7]. Symptoms of neurodegeneration in patients usually occur months or years after the incidence of infection. Strong evidence indicates an essential role of neuroinflammation in the pathogenesis of progressive neurodegeneration [8-16].

To model the sepsis-associated neuropathology, we have previously created a mouse model by a single intraperitoneal (ip) injection of sublethal dose of lipopolysaccharide (LPS, $5 \mathrm{mg} / \mathrm{kg}$ ) [17-19]. Unlike most of acute PD animal models, which often kill neurons too fast [20], this model shows distinct acute and chronic phases of neuroinflammation and recapitulates many cardinal features of Parkinson's disease, thus providing a unique opportunity for studying phase transition of neuroinflammation [21-23].

Numerous reports indicate that brain microglia are the proximal factor for sepsis-associated acute neuroinflammation. Once activated by sepsis via humoral pathway, neural pathway, and blood-brain barrier (BBB) alterations, microglia release a variety of cytokines, chemokines, and free radicals such as nitric oxide $(\mathrm{NO})$ and reactive oxygen species (ROS) [24]. We have demonstrated that tumor necrosis factor alpha (TNF $\alpha$ ) is necessary for initiating acute neuroinflammation after endotoxemia [17]. Although much is known about how endotoxemia affects brain immune functions, a crucial question as to how the transition of acute to chronic neuroinflammation occurs remains unanswered. The purpose of this study was to identify possible immune factors and investigate their mechanisms underlying this immune transition, which could offer new insights and potential therapies for sepsisassociated neurodegeneration.

Interleukin-1 $\beta$ (IL-1 $\beta$ ), one of the potent proinflammatory cytokines, plays crucial roles in amplifying innate and adaptive immunity through its functional receptor IL-1 receptor 1 (IL-1R1) [25]; however, this cytokine could exacerbate tissue injuries in pathological conditions [26-32]. IL-1 $\beta$ precursor protein requires proteolytic cleavage by activated caspase- 1 through the inflammasome, a large intracellular multiprotein complex, to generate mature IL-1 $\beta$, the releasable and bioactive form $[28,30]$. Nod-like receptor protein 3 (NLRP3) inflammasome can be activated by diverse stimuli, such as ATP, crystals, and endoplasmic reticulum (ER) stress, serving as a gate to produce mature IL-1 $\beta$ and involving multiple immune disorders [32-43]. The important role of NLRP3 inflammasome in mediating neurodegeneration produced by several toxins, including intracranial injection of LPS [44, 45], has been described. However, how precisely NLRP3-IL$1 \beta$ impacts endotoxemia-elicited acut-chronic neuroimmune phase transition, which dominates the following progressive neurodegeneration, is still unknown. Thus, this study will provide the first evidence unveiling a novel role NLRP3-IL-1 $\beta$ axis in mediating sepsisassociated brain immune dynamic changes.

In this study, we investigated roles of the NLRP3-IL$1 \beta$ signaling pathway in the transition of acute to chronic neuroinflammation using the peripheral LPSinduced mouse model [17, 21, 23]. We uncovered several unique changes of microglial NLRP3-generated IL-1 $\beta$ in response to LPS treatment in vitro and in vivo, including a delayed increase in the production and release of mature IL-1 $\beta$ compared with most other proinflammatory cytokines, and differential regulated precursor processing pattern in response to different doses of LPS. Moreover, genetic or pharmacological inhibition of either NLRP3 or IL-1R1 did not prevent the initiation of acute neuroinflammation but abolished long-term chronic neuroinflammation and subsequent neurodegeneration. To the best of our knowledge, this study provides the first evidence showing a novel role of NLRP3-IL-1 $\beta$ in mediating the transition from acute to chronic neuroinflammation incited by sepsis.

\section{Methods}

\section{Animals}

Male C57BL/6 J, $\mathrm{NLRP3}^{-/-}$, and IL-1R1 ${ }^{-/-}$mice at the age of 10- to 12-week-old were obtained from The Jackson Laboratory (Bar Harbor, Maine). All housing and breeding procedures and experimental protocols 
were approved by IACUC (Institutional Animal Care and Use Committee) of NIH (National Institutes of Health).

\section{Reagents}

LPS (Escherichia coil O111:B4) used for cell culture studies was purchased from Calbiochem (San Diego, CA; cat\# 437627) and for animal studies was purchased from Sigma-Aldrich (St. Louis, Mo; cat\# L3012). Antityrosine hydroxylase (TH) and anti-Iba-1 were purchased form EMD Millipore (Burlington, MA) and Wako (Richmond, VA), respectively. The secondary antibodies were purchased from Vector Laboratories (Burlingame, CA). The rat anti-mouse $\mathrm{CD}-11 \mathrm{~b}$ antibody was purchased from abD Serotec (Raleigh, NC, cat\# MCA711G). Anti-pro-IL-1 $\beta$, anti-alpha-synuclein ( $\alpha$-synuclein), and anti-3-Nitrotyrosine (3-NT) antibodies were purchased from Abcam (Cambridge, MA). Mouse interleukin-1 receptor antagonist (IL-1Ra), NLRP3 inhibitor MCC950, caspase-1 inhibitor Z-YVAD, IRE1 $\alpha$ (inositol-requiring enzyme $1 \alpha$ ) inhibitor $4 \mu 8 \mathrm{C}$, TNF- $\alpha$, and IL- $1 \beta$ ELISA kits were purchased from R\&D Systems (Minneapolis, MN). Tauroursodeoxycholic acid (TUDC) was from Selleckchem (Houston, TX). Mouse IL-1 $\beta$ pro-form ELISA kit was from eBioScience (San Diego, California). Recombinant mouse IL-1 $\beta$ was from BioLegend (San Diego, CA). Cell culture ingredients were obtained from Invitrogen (San Diego, CA). All other reagents came from Sigma Chemical Co. (St. Louis, MO).

\section{Animal treatment}

Mice, housed in a $12 \mathrm{~h}$ light/dark cycle for 1 week, received a single intraperitoneal injection of LPS $\left[1 \mathrm{mg} / \mathrm{kg}\left(3 \times 10^{6} \mathrm{EU} / \mathrm{kg}\right)\right.$ or $5 \mathrm{mg} / \mathrm{kg}\left(15 \times 10^{6} \mathrm{EU} /\right.$ $\mathrm{kg})$ ] or vehicle (PBS solutions). At different time points after LPS injection, mice were euthanized by Fatal-Plus overdose followed by cardiac perfusion with PBS (for mRNA and protein analysis) or formaldehyde (for IHC) and brains were collected. Brains for IHC were further post-fixed with $4 \%$ paraformaldehyde at $4{ }^{\circ} \mathrm{C}$ for $48 \mathrm{~h}$, and subsequently immersed in $30 \%$ sucrose until the brains sank to the bottom of the container. Coronal sections $(35 \mu \mathrm{m})$ encompassing $\mathrm{SN}$ pars compacta (SNpc) and hippocampus (Hip) were cut at $35 \mu \mathrm{m}$ and stored in PBS.

\section{Primary mouse mesencephalic neuron-glial cultures}

Neuron-glial cultures were prepared from the ventral mesencephalic tissues as previously described [46]. Ventral mesencephalic tissues were dissected from embryonic day $14 \pm 0.5$ and then dissociated with a mild mechanical trituration in ice-cold MEM. Cells were seeded to poly-D-lysine-coated 24-well $\left(6.5 \times 10^{5} /\right.$ well $)$ plates with $0.5 \mathrm{ml} /$ well of maintenance medium and place it in a humidified $37{ }^{\circ} \mathrm{C}, 5 \% \mathrm{CO}_{2}$ incubator. Three days later, neuron-glia cultures were replenished with $0.5 \mathrm{ml} /$ well fresh medium and were used for treatment at 7 days after their initial seeding. The composition of major cell types at the time of treatment was estimated by visual counting of immunostained cells with antibodies against cell-type specific markers: 11\% microglia, $48 \%$ astrocytes, and $41 \%$ neurons, where approximately $1 \%$ of neurons were tyrosine hydroxylaseimmunoreactive (TH-ir).

\section{Primary mouse mixed glial cultures}

Primary mixed glial cultures were prepared by a previously described method [47]. Whole brains of postnatal day 1 neonates of C57BL/6 J mice, after stripping blood vessels and meninges, were dissociated by trituration in DMEM/F12 media. Cells were seeded to poly-D-lysinecoated 24-well $\left(5.5 \times 10^{5} /\right.$ well $)$ plates with $0.5 \mathrm{ml} /$ well of DMEM/F12 mixed glial culture media and maintained in a humidified $37{ }^{\circ} \mathrm{C}, 5 \% \mathrm{CO}_{2}$ incubator. The medium was changed every 3 days with $1 \mathrm{ml} /$ well of DMEM/F12 mixed glial culture media. Cultures were ready for treatment at 14 days after initial seeding. Based on the estimation by immunostained cells with specific microglia marker (Iba-1) and astrocyte marker (GFAP), mixed glia cultures contain about $20 \%$ microglia and $80 \%$ astrocytes.

\section{Immunohistochemistry and double-labeling immunofluorescence of brain slices}

Free-floating $35 \mu \mathrm{m}$ coronal brain slices encompassing $\mathrm{SNpc}$ and Hip regions were subjected to immunostaining as described previously [12]. After washing (two times) with PBS, the brain slices were treated with $1 \%$ hydrogen peroxide for $10 \mathrm{~min}$. The slices were again washed (three times) with PBS and then incubated for 20 min with blocking solution (PBS containing 1\% bovine serum albumin, $0.4 \%$ Triton $\mathrm{X}-100$, and $4 \%$ appropriate serum to block the non-specific binding). The slices were incubated overnight at $4{ }^{\circ} \mathrm{C}$ with rabbit polyclonal antibody against tyrosine hydroxylase (TH) diluted (1:5000, Dopaminergic neuron marker), Iba-1 (1: 5000, microglia marker), Phospho alpha-synuclein (S129) (1:5000), or rat monoclonal antibody against mouse CD11b (1:15000, microglia marker), in antibody diluents (DAKO), and then the slices were washed (three times) for 10 min each time in PBS. The slices were next incubated for $1 \mathrm{~h}$ with PBS containing 0.3\% Triton X100 and the appropriate biotinylated secondary antibody (goat anti-rabbit antibody, 1:227; horse anti-rat, 1:227). After washing (three times) with PBS, the slices were incubated for $1 \mathrm{~h}$ with the Vectastain $A B C$ reagents (Vector Laboratory, Burlingame, CA) diluted in PBS 
containing $0.3 \%$ Triton $\mathrm{X}-100$. To visualize the signal, the slices were incubated with 3,3'-diaminobenzidine and urea-hydrogen peroxide tablets dissolved in water. For morphological analysis, digital images were acquired under microscope (Nikon) connected to a Leica Aperio AT2 scanner.

For immunofluorescence, brain slices were incubated for $20 \mathrm{~min}$ in blocking solution to block non-specific binding. Slices were immunostained overnight at $4{ }^{\circ} \mathrm{C}$ with rabbit polyclonal antibodies against TH (1:5000) and co-labeled with a mouse monoclonal antibody against 3-nitrotyrosine (3-NT) (1: 1000). Antibodies were detected and visualized using Alexa Fluor 594 goat anti-rabbit IgG (1:750), or Alexa Fluor 488 goat antimouse IgG (1:750) secondary antibodies. The images were acquired using an inverted confocal microscope (Zeiss LSM 780). The intensities of Iba-1, CD-11b, Ser129 phosphorylated $\alpha$-synuclein, and immunofluorescence were analyzed using ImageJ software.

\section{Immunocytochemistry of cell cultures}

Cultures were fixed with 3.7\% formaldehyde in PBS for $20 \mathrm{~min}$. After washing (two times) with PBS, the cultures were treated with $1 \%$ hydrogen peroxide for $10 \mathrm{~min}$. The cultures were again washed (three times) with PBS and then incubated for $20 \mathrm{~min}$ with blocking solution. The fixed cultures were immunostained overnight at $4{ }^{\circ} \mathrm{C}$ with rabbit polyclonal antibodies against either TH (1: 5000 ) or rat monoclonal antibody against mouse CD$11 \mathrm{~b}(1: 15000)$ in antibody diluents. Secondary antibody (1:227; Vector Laboratory) was added, amplified with Vectastain $A B C$ reagents (Vector Laboratory), and visualized with 3,3'-diaminobenzidine (DAB). For morphological analysis and cell counting, images were acquired under microscope (Nikon) connected to a Leica Aperio AT2 scanner. The intensity of $\mathrm{CD}-11 \mathrm{~b}$ was analyzed using ImageJ software.

\section{Real-time RT-PCR analysis}

Total RNA was extracted from the mouse brain or cell cultures by using a RNeasy Mini Kit from QIAGEN (Valencia, CA) to detect the level of TNF- $\alpha$, IL-1 $\beta$, interleukin-6 (IL-6), monocyte chemoattractant protein1 (MCP-1), major histocompatibility complex II (MHCII), and NOX2 (gp91) according to the previous description [47]. Total RNA was reversely transcribed with MuLV reverse transcriptase and oligo-dT primers. Then SYBR green PCR master mix was used for realtime PCR analysis. The primer sequences were as follow: GAPDH F (5' TTC AAC GGC ACA GTC AAG GC 3'), GAPDH R (5' GAC TCC ACG ACA TAC TCA GCA CC $\left.3^{\prime}\right)$, TNF- $\alpha$ F (5' GAC CCT CAC ACT CAG ATC ATC TTC T 3'), TNF- $\alpha$ R (5' CCT CCA CTT GGT GGT TTG CT 3'), IL-1 $\beta$ F (5' CTG GTG TGT GAC
GTT CCC ATT A 3'), IL-1ß R (5' CCG ACA GCA CGA GGC TTT 3'), MHC-II F (5' CCG TCA CAG GAG TCA GAA AGG 3'), MHC-II R (5' CGG AGC AGA GAC ATT CAG GTC 3'), NOX2 F (5' GAT TCA AGA TGG AGG TGG GAC 3'), NOX2 R (5' GGT CAG TGT GAA TGG GTG CC 3'), MCP-1 F (5' TTT GAA TGT GAA GTT GAC CCG 3'), and MCP-1 R (5' GAA GTG CTT GAG GTG GTT GTG 3'). Real-time PCR amplification was performed using SYBR Green PCR Master Mix and QuantStudio 6 Flex Real-Time PCR System (Applied Biosystems, Foster City, CA, USA) according to manufacturer's protocols. Amplifications were done at $95{ }^{\circ} \mathrm{C}$ for $10 \mathrm{~s}, 55^{\circ} \mathrm{C}$ for $30 \mathrm{~s}$, and $72{ }^{\circ} \mathrm{C}$ for $30 \mathrm{~s}$ for 40 cycles. All samples were tested in duplicate and normalized with GAPDH using the $2^{-\Delta \Delta \mathrm{Ct}}$ method. Fold changes for each treatment were normalized to the control.

\section{Pro-IL-1 $\beta$ Western blot analysis}

Tissues were homogenized in lysis buffer containing protease inhibitor cocktail. Equal protein from each half brain was separated by Bis-Tris-polyacrylamide electrophoresis gel, and then transferred to polyvinylidene difluoride (PVDF) membranes. Membranes were blocked with $5 \%$ non-fat milk and probed overnight at $4{ }^{\circ} \mathrm{C}$ with anti-pro-IL-1 $\beta$ antibody. Membranes were followed by incubating with secondary antirabbit IgG for $1 \mathrm{~h}$. ECL Plus reagents were used as a detection system. Relative band intensities were quantified by ImageJ.

\section{Stereological and manual counting assessments of neurodegeneration}

Dopaminergic neurons of the $\mathrm{SNpc}$ were identified through $\mathrm{TH}$ immunohistochemistry. The number of $\mathrm{TH}$-immunoreacted (TH-ir) neurons in SNpc between saline and LPS-injected groups was counted with both optical fractionator and manual counting ways. For stereological counts, a total of eight sections containing the $\mathrm{SNpc}$ were sampled at $105-\mu \mathrm{m}$ intervals. We used an optical fractionator method on an Olympus BX50 stereological microscope to estimate $\mathrm{TH}$-ir neurons within user-defined boundaries [21-23]. Systematic random sampling of sites with an unbiased counting frame $(100 \mu \mathrm{m} \times 100 \mu \mathrm{m})$ was conducted within defined boundaries of the SN. The guard zone was set at $2 \mu \mathrm{m}$ and the dissector height was $11 \mu \mathrm{m}$. The counts were performed with an Olympus BX50 microscope with a $60 \times 1.4 \mathrm{NA}$ oil immersion objective. The coefficient of error values was less than 0.1. For manual count, three individuals performed counting in a double-blind manner [46]. 


\section{Statistical analysis}

Data was presented as the mean \pm SEM. Comparison of more than two groups was performed using one-way ANOVA followed by Bonferroni post hoc multiple comparison test. Comparisons of more than two parameters were performed by two-way ANOVA analysis followed by Bonferroni post hoc multiple comparison test. Data were analyzed using Prism (v7.00, GraphPad, San Diego, CA). $P$ values less than or equal to 0.05 were considered statistically significant.

\section{Results}

Brain-delayed mature IL-1 $\beta$ levels, but not initial acute proinflammatory response, are peripheral LPS dosedependent

Mice received a single intraperitoneal injection of either 1 or $5 \mathrm{mg} / \mathrm{kg}$ of LPS to produce either mild or severe endotoxemia. No difference in the increases in brain mRNA levels of TNF $\alpha$, IL-6, MCP-1, and IL- $1 \beta$ were observed between LPS 1 and $5 \mathrm{mg} / \mathrm{kg}$ groups at $1 \mathrm{~h}$ after injection, indicating that brain initial proinflammatory responses are not related to LPS doses (Fig. 1a-d). Different from most proinflammatory cytokines, the production of mature IL- $1 \beta$ is inflammasome-dependent via limited proteolysis of its precursor protein. Therefore, we compared time-course expression of not only IL- $1 \beta$ mRNA and precursor but also IL- $1 \beta$ mature form, to determine whether endotoxemia severity affects brain mature IL-1 $\beta$ levels. We found that 1 and $5 \mathrm{mg} / \mathrm{kg}$ of LPS-elicited increases in IL-1 $\beta$ mRNA and precursor levels are similar (Fig. 1d, e and Additional file 1: Figure S1). By contrast, high dose of LPS produced much higher brain mature IL-1 $\beta$ than that of low dose of LPS during 7-11 h after LPS injection (Fig. 1f). After $24 \mathrm{~h}$, brain mature IL- $1 \beta$ concentrations were too low to detect by the ELISA kit.

For more detailed mechanistic studies on the processing of IL-1 $\beta$ protein, we employed primary mouse mixglial cultures, which mainly contain $20 \%$ microglia and $80 \%$ astroglia. There are two reasons for using mix-glial cultures, instead of enriched microglial cultures. First, reports indicate that microglia are the main source of IL-1 $\beta$ production in the brain after peripheral LPS injection [48-50] and in cell cultures upon LPS stimulation [39]. Second, the presence of astroglia helps the survival and stabilization of microglia in cultures [51]. Two concentrations of LPS (10 and $1000 \mathrm{ng} / \mathrm{ml}$ ), which produce different degrees of inflammatory responses, were added to the cultures. And then IL-1 $\beta$ mRNA, precursor protein, and mature IL- $1 \beta$ were measured at different times afterwards. Similar to brain tissues, mix-glial cultures produced comparable increases in the expression of IL$1 \beta$ mRNA and precursor levels between high and low concentrations of LPS treatment (Fig. 1g, h). By contrast, high concentrations of LPS caused a larger delayed increase in the supernatant IL-1 $\beta$ level than that of low concentrations of LPS (Fig. 1i).

\section{High dose, but not low dose, of peripheral LPS causes long-lasting nigral microglial activation}

In vitro and in vivo findings prompted us to further determine whether the dose-related increase in mature IL- $1 \beta$ could be related to the transition of acute to chronic inflammation. To obtain evidence supporting this hypothesis, we investigated the persistence of microglia activation after 1 and $5 \mathrm{mg} / \mathrm{kg}$ LPS treatment. For monitoring microglial activation, immunostaining of Iba-1 (ionized calcium binding adaptor molecule 1) was performed at acute stage ( $6 \mathrm{~h}$ after LPS) and CD-11b ( $\alpha$ chain of Mac1 receptor) was used as a marker for the chronic stage ( 1 week after LPS). The reason for using two different markers at different stages is based on our previous reports indicating that microglial Iba-1 but not CD-11b expression was acutely enhanced after LPS injection. During the acute inflammation stage, the level of CD-11b at $6 \mathrm{~h}$ after LPS was too low for immunostaining. By contrast, the increase of CD-11b expression was much higher than that of Iba- 1 at 1 week and later time points [21, 52]. In this study, Iba-1 staining quantification revealed that acute microglial activation in the substantia nigra was apparent at $6 \mathrm{~h}$ after LPS injection, but there were no differences between LPS 1 and $5 \mathrm{mg} / \mathrm{kg}$ groups (Fig. 1j). One week later, nigral microglial morphology in $1 \mathrm{mg} / \mathrm{kg}$ LPS group was similar to that of saline group, suggesting that acute neuroinflammation had resolved (Fig. 1k). In contrast, protracted neuroinflammation occurred in $5 \mathrm{mg} / \mathrm{kg}$ LPS group, which showed clear sustained activation of microglia in the SN region (Fig. 1k). Thus, brain-delayed mature IL-1 $\beta$ levels and prolonged neuroinflammation are both affected by LPS in a dose-dependent manner, which is consistent with the idea that IL-1 $\beta$ may serve as a critical factor in the transition from acute to chronic neuroinflammation.

\section{Deficiency of NLRP3 reduces LPS-elicited increase in IL-1 $\beta$, but not IL-1a, levels}

Among inflammasome family members, NLRP3 inflammasome is abundantly expressed and plays a key role in IL-1 $\beta$ processing in the brain [53-55]. However, whether elevated brain IL-1 $\beta$ levels incited by endotoxemia are NLRP3-dependent remain unclear. Since brain mature IL-1 $\beta$ levels peaked around 7-11 $\mathrm{h}$ after LPS injections (Fig. 1f), we compared $9 \mathrm{~h}$ brain mature IL-1 $\beta$ between NLRP3-deficient $\left(\mathrm{NLRP}^{-/-}\right.$) and WT mice and found that $\mathrm{NLRP}^{-/}$mice generated significantly less brain mature IL-1 $\beta$ than that of WT mice (Fig. 2a). In mixglial cultures, either genetic knockout of NLRP3 or pharmacological inhibition of NLRP3 by MCC950 (an 
Brain tissue studies

A

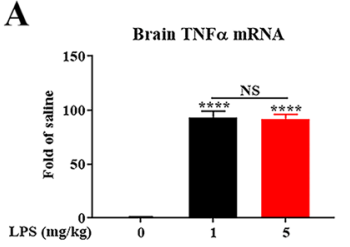

D

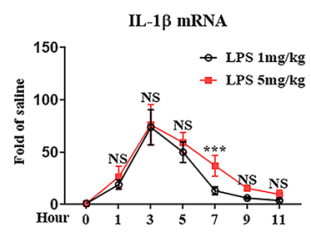

B

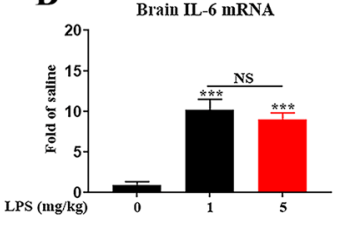

E

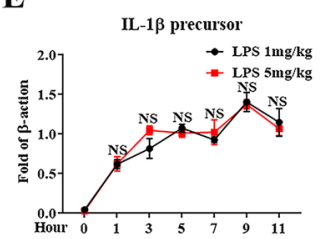

C

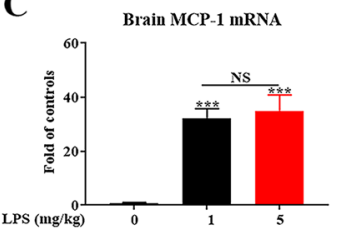

F

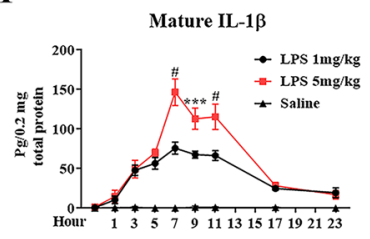

Mix-glial culture studies
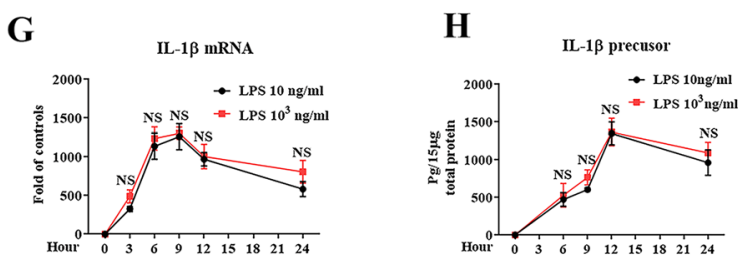

I

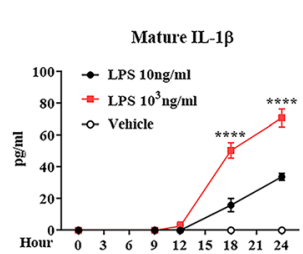

J Nigral Iba-1-ir microglia $6 \mathrm{~h}$ after LPS
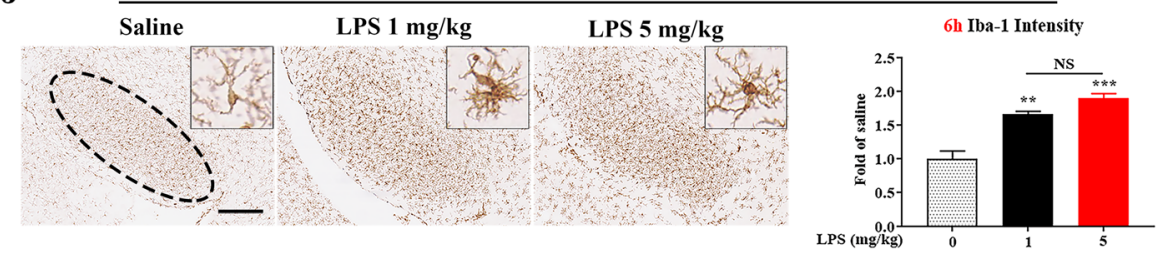

K

Nigral CD-11b-ir microglia 1 week after LPS
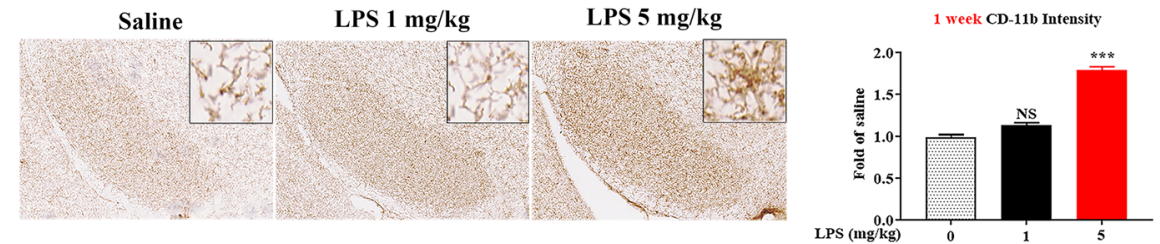

Fig. 1 Peripheral LPS dose-dependently increases brain mature IL-1 $\beta$ production and causes sustained nigral microglial activation. In vivo cytokine measurements (a-f): At $1 \mathrm{~h}$ after injection of LPS (1 or $5 \mathrm{mg} / \mathrm{kg}$, ip) or saline vehicle in C57BL/6 J mice, mRNA levels of TNFa (a), IL-6 (b), and MCP-1 (c) were detected by qPCR in brain tissues ( $n=4$ /group). ${ }^{* *} p<0.001$ and ${ }^{* * *} p<0.001$ compared with saline vehicle group. No significant difference (NS) between LPS 1 and $5 \mathrm{mg} / \mathrm{kg}$ groups. One-way ANOVA followed by Bonferroni post hoc multiple comparison test. Levels of IL-1 $\beta$ mRNA (d), and its precursor (d) and mature IL-1 $1 \beta(F)$ were measured in brain tissues at indicated time points by qPCR, Western blot quantification, and ELISA, respectively ( $n=3-5 /$ group for each timepoint). ${ }^{* *} p<0.001$, $\# p<0.0001$, or NS compared with LPS 1 mg/kg group. Two-way ANOVA followed by Bonferroni post hoc multiple comparison test. In vitro IL-1 $\beta$ measurements (g-i): In C57BL/6 J mix-glia cultures after LPS $\left(10 \mathrm{ng} / \mathrm{ml}\right.$ or $\left.10^{3} \mathrm{ng} / \mathrm{ml}\right)$, or vehicle medium treatment, mRNA $(\mathbf{g})$, supernatant precursor $(\mathbf{h})$, and mature form (i) of IL-1 $\beta$ were determined at indicated time points by qPCR or ELISA, respectively. Results were from three independent experiments. ${ }^{* * *} p<0.001$ compared with LPS 10 ng/ $\mathrm{ml}$ group. Two-way ANOVA followed by Bonferroni post hoc multiple comparison test. In vivo microglial activation (j, k): At $6 \mathrm{~h}$ and 1 week after injection of LPS (1 or $5 \mathrm{mg} / \mathrm{kg}$, ip) or saline vehicle in C57BL/6 J mice ( $n=3 /$ group for each timepoint), nigral microglial lba-1 (j) or CD-11b (k) immunostaining was performed, respectively. Representative images were shown. Scale bar $=300 \mu \mathrm{m}$. The histograms showed the density of Iba1 (j) or CD-11b (k) quantified by with ImageJ. ${ }^{* *} p<0.01$ and ${ }^{* *} p<0.001$ compared with saline vehicle group, and NS between LPS 1 and 5 mg/ kg groups. One-way ANOVA followed by Bonferroni post hoc multiple comparison test 


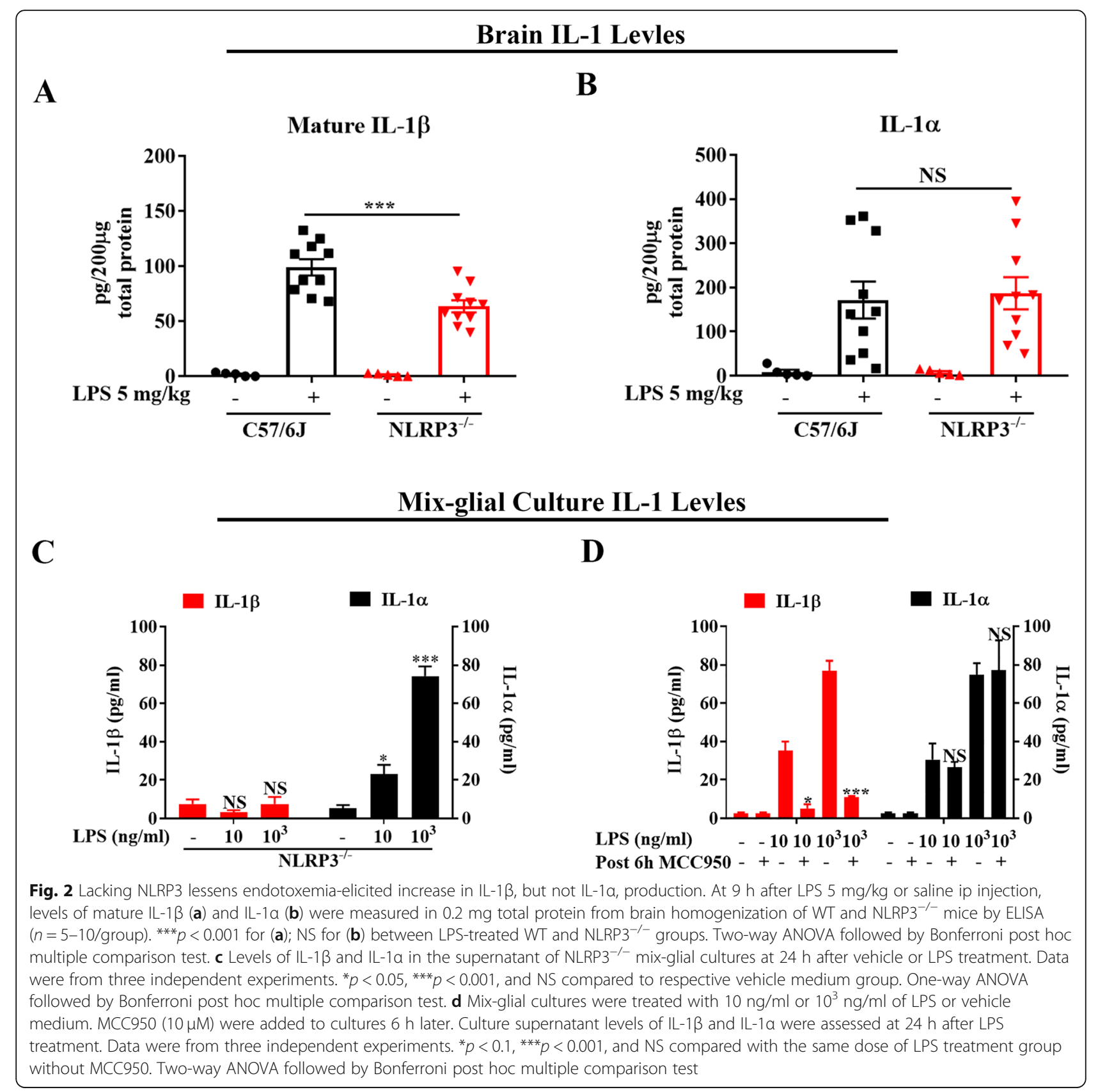

NLRP3 inhibitor) [56] significantly reduced LPSstimulated mature IL- $1 \beta$ release (Fig. $2 c, d$ ). We also measured LPS-elicited increase in brain and culture supernatant levels of IL- $1 \alpha$, another IL- 1 family member, which is the ligand of IL-1R1 too [29], to determine whether processing of this cytokine is NLRP3dependent. LPS-elicited IL-1 $\beta$ levels were decreased both in brain tissues and the supernatant of mix-glial cultures in the absence of NLRP3. By contrast, brain IL- $1 \alpha$ productions were independent of NLRP3 (Fig. 2b, c). Similarly, post-treatment of MCC950 reduced the production of IL-1 $\beta$ but not IL-1 $\alpha$ (Fig. $2 d$ ).
ER stress mediates LPS alone-induced NLRP3-dependent IL-1 $\beta$ production

We first determined whether LPS enhances the expression of NLRP3 and found that mRNA levels of NLRP3 were greatly increased and peaked at $3 \mathrm{~h}$ after LPS treatment in mixed glial cultures (Additional file 2: Figure S2a). Additional studies showed that YVAD (a caspase-1 inhibitor) significantly repressed LPS-induced increase in the release of mature IL-1 $\beta$ (Additional file 2: Figure S2b). These results indicate the involvement of the NLRP3-caspase-1 pathway in LPS alone-induced microglial mature IL-1 $\beta$ release. In fact, we have 
performed Western blot analysis to measure levels of NLRP3, caspase-1 (in pro and mature form), but not ASC (antibody used did not work), in both microgliaenriched cultures and in intact brains and dosedependent increases in both NLRP3 and mature form of caspase-1. LPS-elicited increase in activated caspase-1 and mature IL-1 $\beta$ levels were significantly reduced in the presence of the NLRP3 inhibitor MCC950 in primary microglia-enriched cultures. These data were included in a separate paper submitted to another journal for publication (Gao et al., submitted for publication).

Most investigations have demonstrated that NLRP3 inflammasome-dependent processing of IL-1 $\beta$ precursor to mature form requires secondary stimulating agents, such as ATP, or pore-forming toxins, to activate the NLRP3-caspase-1 pathway [39]. Interestingly, LPS alone in our study can trigger microglial mature IL- $1 \beta$ release in the absence of known NLRP3 activators. We were wondering the mechanism underlying LPS aloneinduced microglial IL-1 $\beta$ maturation. Furthermore, a recent report indicated that ER stress can activate NLRP3 inflammasome in macrophage stimulated by pathogen alone in the absence of NLRP3 inflammasome activators [43]. Additionally, increased levels of ER stress makers were observed in the brain after LPS ip injection and relief of ER stress decreased brain cytokine production including IL-1 $\beta$ [57]. Therefore, we investigated a potential role of ER stress in mediating LPS aloneinduced NLRP3-dependent mature IL- $1 \beta$ production in microglia. Our data showed that LPS-induced mature IL-1 $\beta$ levels declined significantly by post-treatment with ER stress inhibitors either tauroursodeoxycholic acid (TUDC, a chemical chaperon mitigating ER stress) or $4 \mu 8 \mathrm{C}$ (a specific IRE1 $\alpha$ inhibitor), suggesting a role of ER stress in LPS alone-induced microglial activation of NLRP3 inflammasome (Additional file 2: Figure S2c).

\section{The NLRP3- IL-1R1 pathway dictates peripheral LPS- elicited transition from acute to chronic neuroinflammation}

IL-1 $\beta$ acts on two receptors: IL-1R1, a receptor responsible for IL- $1 \beta$ signal transduction via MyD88-NF- $\mathrm{KB}$ and MAPK pathways, and IL-1R2, a decoy receptor that blocks the function of IL-1 $\beta$ [25]. To further elucidate the role of IL-1 $\beta$ in LPS-induced acute-chronic transition of neuroinflammation, we injected wild-type (WT), $\mathrm{NLRP3}^{-/-}$, and IL-1R1 ${ }^{-/-}$mice with LPS (5 mg/kg, ip). This dose of LPS produced prolonged neuroinflammation in WT mice (Fig. 1k). Increased levels of brain mRNA including TNF $\alpha$, IL-6, and MCP-1 measured at $1 \mathrm{~h}$ after LPS injection were similar among these three strains of mice (Additional file 3: Figure S3a-c), except the IL-1 $\beta$ mRNA levels, which were slightly higher in $\mathrm{NLRP}^{-/-}$mice than those in WT mice, perhaps due to a compensatory effect (Additional file 3: Figure S3d). Furthermore, during the acute phase of LPS-elicited neuroinflammation (6 $\mathrm{h}$ after LPS), no difference in microglial activation as shown by enhanced Iba- 1 immunoreactivity in the $\mathrm{SN}$ region was observed between these three strains of mice (Fig. 3a). Thus, sepsis still launches acute proinflammatory response in the brain without the participation of NLRP3 or IL-1R1. By contrast, NLRP3 and IL-1R1 are required for long-term maintenance of microglial activation after sepsis. During the chronic neuroinflammatory phase ( 1 week, 4 and 10 months after LPS), higher levels of CD-11b immunoreactivity and activated morphology of nigral microglia were still evident in WT mice, but not in both NLRP3or IL-1R1-deficent mice (Fig. 3b-d). Taken together, our results from different doses of LPS (Fig. 1), plus data from mutant mice (Figs. 2 and 3), strongly indicate a critical role of the NLRP3-IL1 $\beta$-IL-1R1 pathway in mediating the transition from acute to chronic neuroinflammation incited by severe endotoxemia.

\section{Genetic/pharmacological inhibition of NLRP3 or IL-1R1 represses LPS-elicited production of chronic inflammatory mediators in neuron-glial cultures}

To determine potential inflammatory factors mediating NLRP3-IL-1 $\beta$-elicited chronic neuroinflammation, we performed in vitro studies using mouse primary midbrain neuron-glial cultures containing approximately $40 \%$ neurons, $10 \%$ microglia, and $50 \%$ astroglia. To observe clearer neuronal damage and reactive microgliosis, we treated neuron-glial cultures with a higher concentration of LPS $(20 \mathrm{ng} / \mathrm{ml})$. In this series of studies, we assessed the consequence of lacking either NLRP3 or IL-1R1 on the induction of acute factors such as TNF $\alpha$, and delayed factors including MHC-II, NOX2 (gp91), and Mac1. These delayed factors are necessary for sustained reactive microgliosis and long-lasting neuroinflammation [11, 21, 58-67].

We first demonstrated that the lack of NLRP3 or IL1R1 did not impede the initiation of LPS-elicited acute immune response. LPS stimulated a large increase of TNF $\alpha$ level measured at its peak release level ( $4 \mathrm{~h}$ after LPS) in cultures prepared from WT, NLRP3 ${ }^{-/}$, and IL$1 \mathrm{R} 1^{-/-}$mice; however, no difference in the amount of increase was observed among these three groups (Fig. 4a). There was a delayed increase in the release of IL-1 $\beta$ in WT and $\mathrm{IL}-1 \mathrm{R} 1^{-/-}$, but not in $\mathrm{NLRR}^{-/-}$cultures (Fig. 4b). Furthermore, addition of a NLRP3 inhibitor MCC950 to the cultures diminished LPS-elicited IL-1 $\beta$ production (Fig. 4c).

Several late-expressed genes, including MHC-II, NOX2, and Mac1, which are involved in mediating chronic neuroinflammation were determined using NLRP3 or IL-1R1 inhibitors. To avoid interfering with 
$\mathbf{A}$

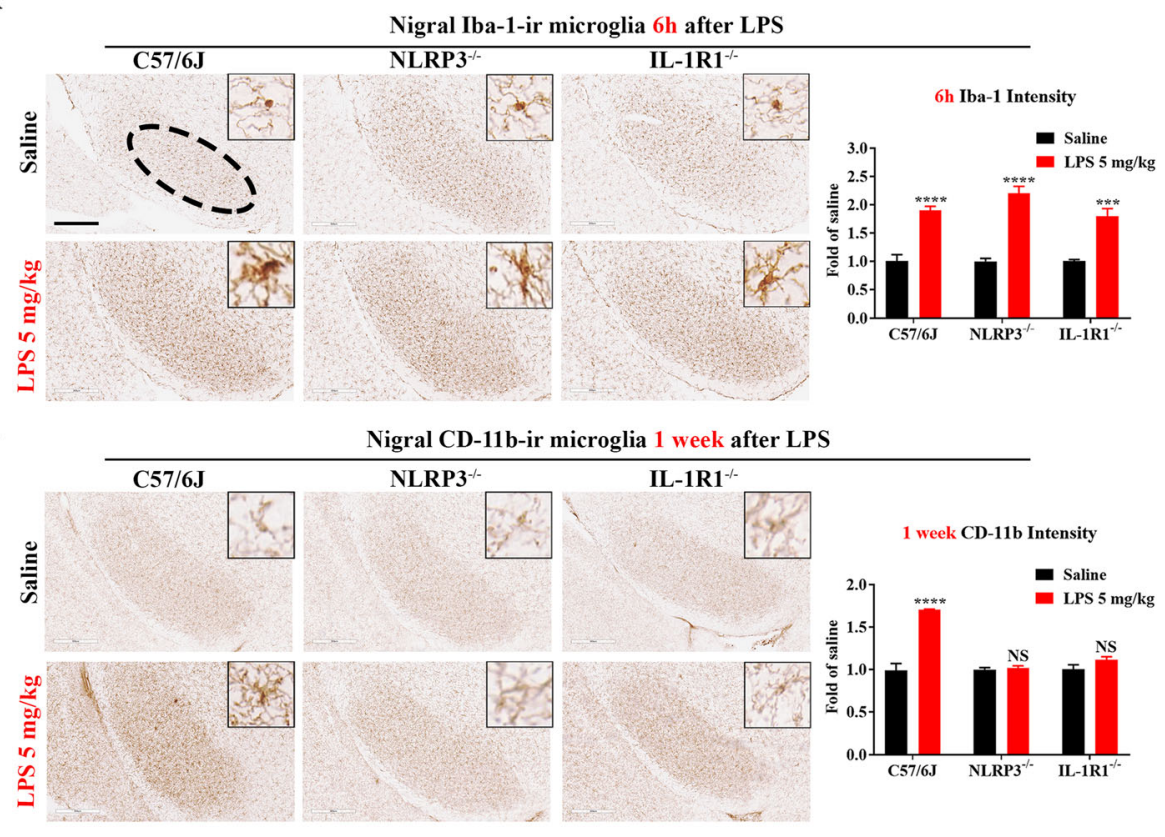

C
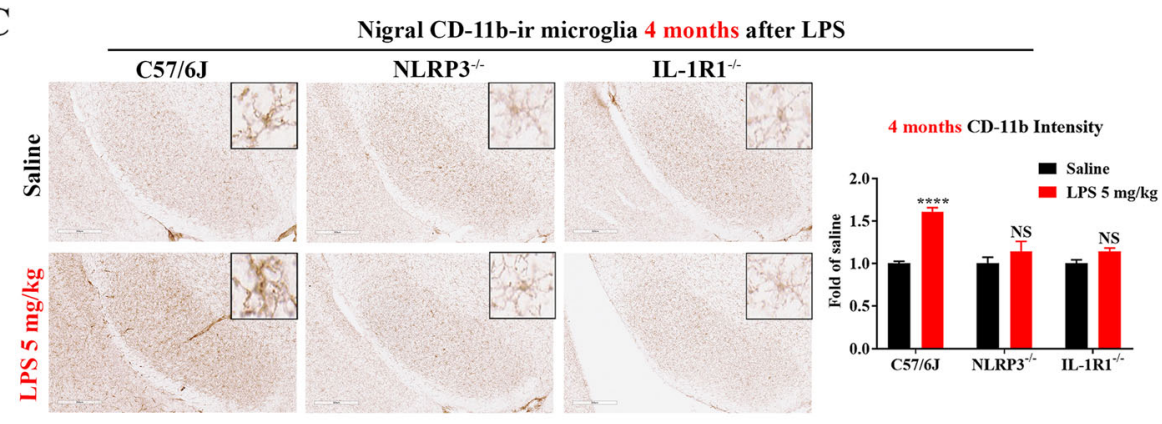

D

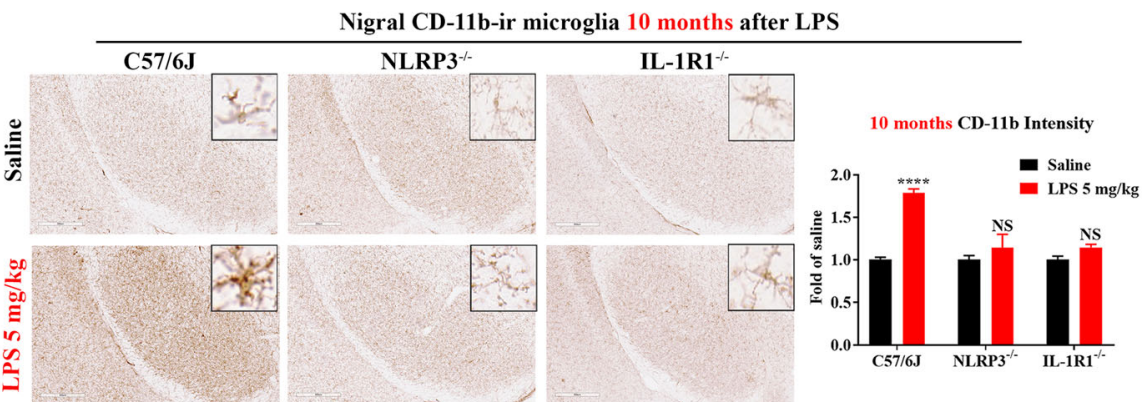

Fig. 3 High dose LPS injection produces long-lasting microglial activation in WT mice, but not in $\mathrm{NLRP3}^{-/-}$or IL-1R1 ${ }^{-/-}$mice. Following a single injection of LPS (5 mg/kg; ip) or saline vehicle, mice were perfused $6 \mathrm{~h}, 1$ week, 4 and 10 months thereafter for nigral microglial Iba- 1 or CD-11b immunostaining ( $n=3 /$ group for each time point). Representative images at each time point were shown (a-d). Scale bar $=300 \mu \mathrm{m}$. Results are expressed as folds of time-matched vehicle control. Histograms represent degree of microglial activation quantified by measuring the density of Iba-1 or CD-1 1b staining with ImageJ. ${ }^{* * *} p<0.001,{ }^{* * * *} p<0.0001$, and NS compared to respective saline vehicle group. Two-way ANOVA followed by Bonferroni post hoc multiple comparison test

LPS-elicited acute neuroinflammatory response, MCC950 was added $6 \mathrm{~h}$ and an IL-1 receptor antagonist (IL-1Ra) was added $9 \mathrm{~h}$ after LPS treatment. These two posttreatment time points reflect the peak of IL-1 $\beta$ processing and the peak of IL- $1 \beta$ release, respectively. The blockade of the NLRP3-IL-1 $\beta$ pathway by either preventing the production or inhibiting the action of IL-1 $\beta$ greatly reduced LPS-induced 


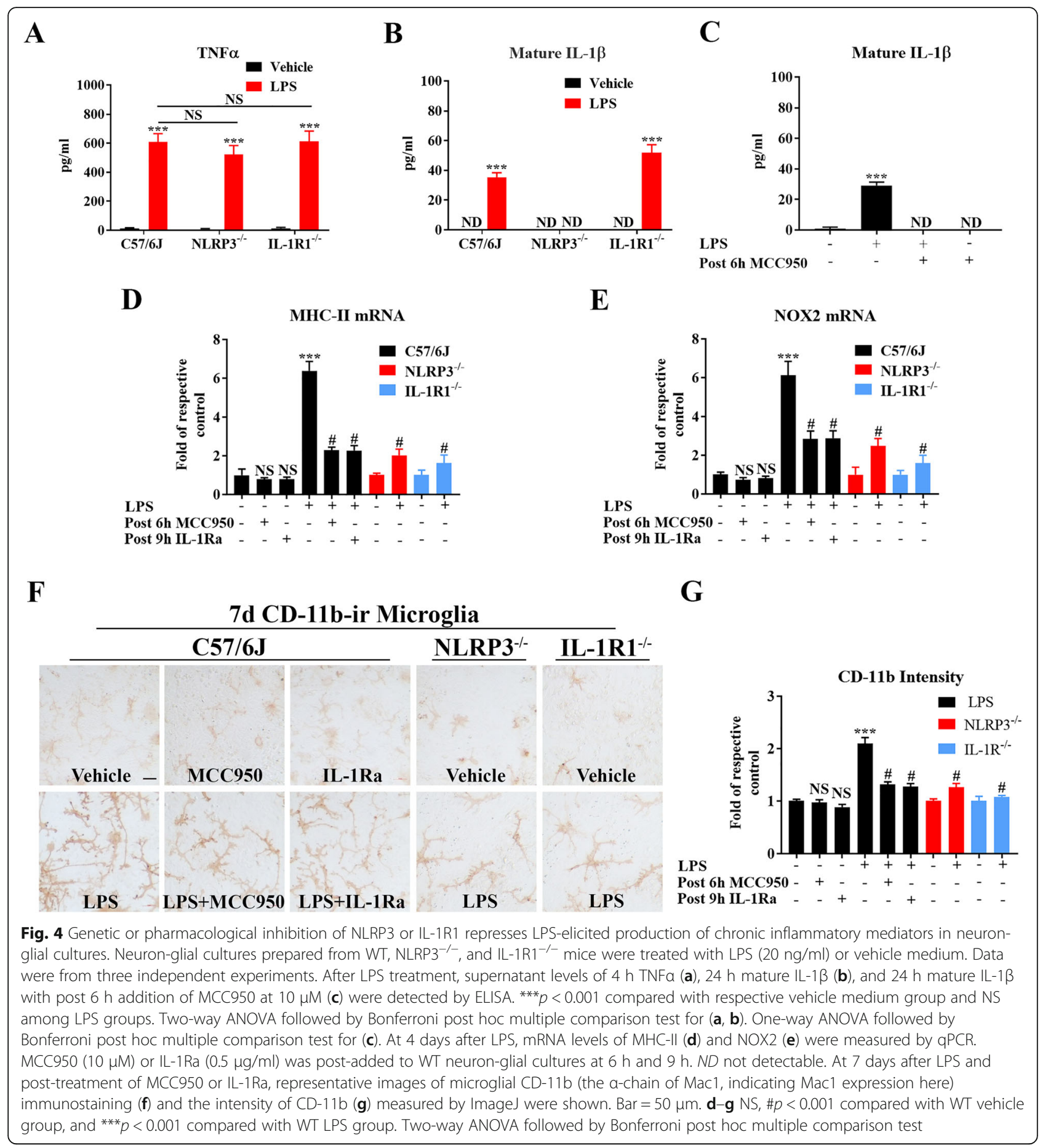

upregulated expression of MHC-II and NOX2 mRNA levels and immunoreactivity of $\mathrm{CD}-11 \mathrm{~b}$ during the chronic phase of neuroinflammation (Fig. $4 \mathrm{~d}-\mathrm{g}$ ). Together, results from in vitro studies are consistent with our in vivo data and further support the concept that the NLRP3-IL-1 $\beta$ signaling pathway is essential in mediating the transition of acute to chronic neuroinflammation.
Genetic mutation or pharmacological inhibition of NLRP3 or IL-1R1 prevents LPS-elicited dopaminergic neurons death

Strong emerging evidence supports the notion that sustained neuroinflammation drives chronic neurodegeneration as mentioned in the introduction. Since the deficiency of NLRP3-IL-1 $\beta$ pathway prevented chronic, but not acute, neuroinflammation after sepsis (Figs. 3, 4, 
and Additional file 2: Figure S2), we next studied whether blockage of generation or action of IL-1 $\beta$ would avoid sepsis-associated neurodegeneration once acute neuroinflammation began.

We first performed an in vitro study by using mouse primary midbrain neuron-glia cultures prepared from WT, $\mathrm{NLRP3}^{-/-}$, or IL-1R1 ${ }^{-/-}$mice as described above. A $40-50 \%$ tyrosine hydroxylase (TH)immunoreactive (ir) neurons (dopaminergic neurons) loss was found at 7 days after LPS treatment in WT cultures. By contrast, LPS failed to produce significant loss of dopaminergic neurons in either $\mathrm{NLRP}^{-/-}$or IL-1R1 $1^{-1-}$ cultures (Fig. 5a, b). Next, following LPS treatment, we post-treated cultures with MCC950 at $6 \mathrm{~h}$ or IL-1Ra at $9 \mathrm{~h}$ after LPS (Fig. $4 \mathrm{~d}$, e). The results showed that 7 days later, LPS-elicited loss of $\mathrm{TH}$-ir neurons was prevented by these two inhibitors (Fig. 5c, d). Therefore, either genetic or pharmacological inhibition of the NLRP3-IL-1 $\beta$ pathway hampered LPS-induced neurotoxicity. We further conducted a rescue study by adding small amounts of recombinant IL-1 $\beta$ to $\mathrm{NLRP3}^{-/-}$neuron-glial cultures at $12 \mathrm{~h}$ after LPS. Lacking NLRP3 prevented LPSelicited loss of dopaminergic neurons, whereas adding IL- $1 \beta$ at $40 \mathrm{pg} / \mathrm{ml}$ resulted in about $50 \%$ dopaminergic neuron loss at 7 days in LPS-treated $\mathrm{NLRP3}^{-/-}$ neuron-glial cultures (Fig. 5e, f). Although the amount of mature IL-1 $\beta$ released to the supernatant are merely $\sim 40 \mathrm{pg} / \mathrm{ml}$ (about $2.2 \times 10^{-13} \mathrm{M}$ ) (Fig. $4 \mathrm{~b}$ ), this little amount of IL- $1 \beta$ is sufficient for causing longlasing neuroinflammation and neuronal loss. The essential role of IL-1 $\beta$ in chronic neuroinflammationmediated neuronal damage was further confirmed in animal studies. The gradual loss of nigral dopaminergic neurons is one of the cardinal features of PD. Ten months after a single injection of LPS, a 30\% loss of nigral dopaminergic neuron was found in WT; however, there was no significant difference between saline and LPS treatment in $\mathrm{NLRP}^{-/-}$or $\mathrm{IL}-1 \mathrm{R} 1^{-/-}$ mice (Fig. 6a-c).

To provide evidence indicating that oxidative stress resulted from sustained chronic neuroinflammation underlies the mechanism of sepsis-associated long-term neurotoxicity, we measured changes of protein nitrosylation $[68,69]$ and $\alpha$-synuclein phosphorylation at position Ser-129 [70], which are critical for the pathogenesis of PD [71-73]. Enhanced nitrosylation of proteins in the nigral region was observed in WT, but not in $\mathrm{NLRP3}^{-/-}$ or IL-1R $1^{-1-}$, mice at 10 months after LPS injections (Fig. 7a and Additional file 4: Figure S4). Besides SN, aggregation of $\alpha$-synuclein in PD patients can develop in different brain regions, such as the hippocampus [74]. Prominent increases in the immunoreactivity of Ser129 phosphorylated $\alpha$-synuclein in SN and hippocampus of WT mice at 10 months after LPS treatment was found. By contrast, LPS did not increase Ser-129 phosphorylated $\alpha$-synuclein-ir in $\mathrm{NLRP}^{-/-}$or IL-1R1 ${ }^{-/-}$mice (Fig. 7b, c).

\section{Discussion}

Failure of immune resolution may lead to chronic brain inflammation and subsequent neurodegenerative diseases, such as Parkinson's or Alzheimer's diseases. Elucidation of the molecular mechanism mediating the transition from acute to chronic neuroinflammation is paramount to further understanding the pathogenesis of these neurodegenerative diseases. Here, we provide the first evidence indicating that NLRP3 inflammasome-generated IL-1 $\beta$ from microglia is the key cytokine in governing the transition of neuroinflammatory phases elicited by severe endotoxemia. NLRP3 gauges the severity of endotoxemia and determines the amount of mature IL- $1 \beta$ to produce from its precursor protein. Excessive release of IL-1 $\beta$ triggers the transition of acute to chronic neuroinflammation and eventually results in progressive neurodegeneration. Our study not only identified a novel role of IL-1 $\beta$ in the pathophysiology of endotoxemiaelicited neuroinflammation but also suggested a new strategy for developing potential therapies for neurodegenerative diseases. A schematic drawing depicting how brain IL- $1 \beta$ levels determine the fate of neuroinflammation induced by endotoxemia is shown in Fig. 8.

\section{Roles of IL- $1 \beta$ in neuroinflammation}

Studies indicate that proinflammatory cytokines/chemokines, such as TNF $\alpha$, IL-6, IL-1 $\beta$, or MCP-1, etc., released of from activated microglia are important mediators for sepsis-associated brain inflammation [75]. This study unveiled a distinct role of IL-1 $\beta$ in the neuroinflammatory process. Unlike TNF $\alpha$, which is necessary in triggering acute neuroinflammation [17], IL-1 $\beta$ is dispensable for the initiation of acute neuroinflammation but is essential for the launch of chronic neuroinflammation in mice with peripheral LPS administration.

Roles of IL-1 $\beta$ in mediating infection-induced acute sickness behaviors, the pathophysiological interactions between brain and immune systems, are well known [76-79]. However, information is limited regarding involvement of IL-1 $\beta$ in the long-term consequences in the brain after severe systemic infections. Previous reports indicate that IL-1 $\beta$ causes neurotoxicity per se or exacerbates pre-existing inflammatory response [80, 81]. However, the concentrations of IL- $1 \beta$ used in these studies were several orders of magnitude higher than the maximal amount that can be produced from 
7d TH-ir Neuron after LPS

A

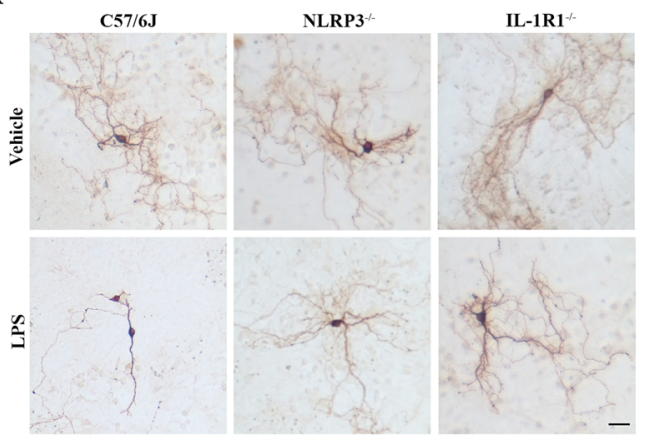

B

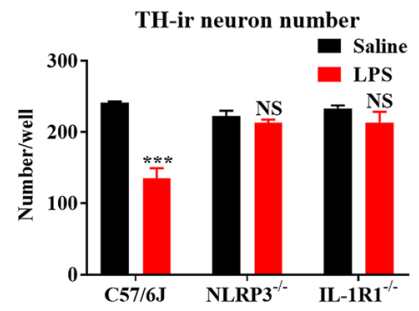

Pharmocological Inhibition Studies

C

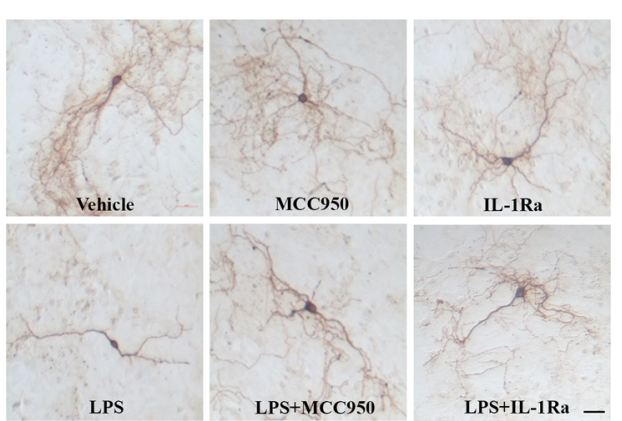

D

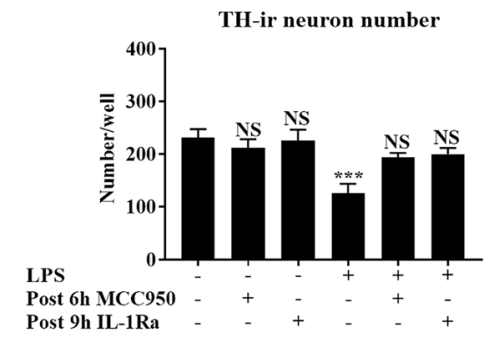

Addition of IL-1 $\beta$ in NLRP3 ${ }^{-/-}$Cultures

E

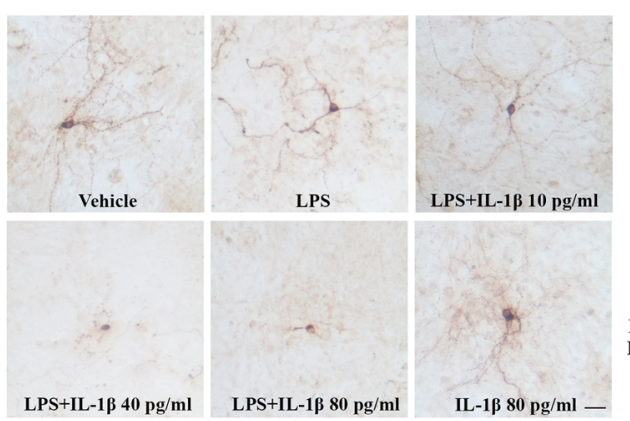

F

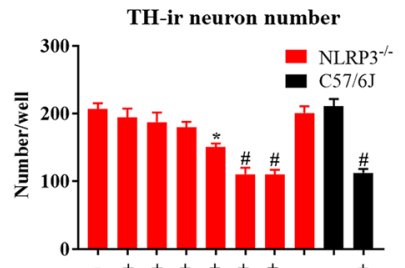

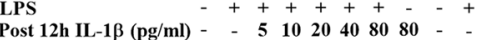

Fig. 5 Genetic or pharmacological inhibition of NLRP3 or IL-1R1 does not affect TNFa release but protects dopaminergic neurons against LPSinduced toxicity in neuron-glia cultures. Neuron-glial cultures prepared from WT, NLRP3 ${ }^{-1}$, and IL-1R1 $1^{-1-}$ mice were treated with LPS (20 ng/ml) or vehicle medium. Data were from three independent experiments. Scale bar $=50 \mu \mathrm{m}$. At 7 days after LPS, representative images of TH immunostaining (dopaminergic neurons) (a) and TH-ir neuron number (b) were shown. At 7 days after LPS injection and post-treatment of MCC950 (10 $\mu \mathrm{M}$ at $6 \mathrm{~h})$ and IL-1Ra $(0.5 \mu \mathrm{g} / \mathrm{ml}$ at $9 \mathrm{~h})$, representative images of TH immunostaining (c) and TH-ir neuron number (d) were shown. $\mathbf{b}, \mathbf{d}{ }^{* * *} p<0.0001$ and NS compared with respective vehicle medium group. Two-way ANOVA followed by Bonferroni post hoc multiple comparison test for (b) and one-way ANOVA followed by Bonferroni post hoc multiple comparison test for (d). At 7 days after LPS and post $12 \mathrm{~h}$ addition of different amounts of recombinant mouse IL-1 $\beta$ to NLRP3 ${ }^{-/}$neuron-glial cultures, representative images of TH immunostaining (e) and TH-ir neuron number $(\mathbf{f}) .{ }^{*} p<0.5$ and $\# p<0.0001$ compared with respective vehicle group. One-way ANOVA followed by Bonferroni post hoc multiple comparison test

brain. Thus, the pathophysiological function of IL-1 $\beta$ remains unclear. In this study, we provided strong evidence demonstrating a novel role of this cytokine in sepsis-induced long-term neuropathology. This conclusion was mainly based on the results from the following two studies.
High and low doses of peripheral LPS produce similar acute inflammation, but generate differential outcomes of sustained chronic inflammation and neurodegeneration

A dose-response study of LPS revealed that 1 and $5 \mathrm{mg} / \mathrm{kg}$ of LPS produced comparable proinflammatory cytokine induction and microglial activation in 


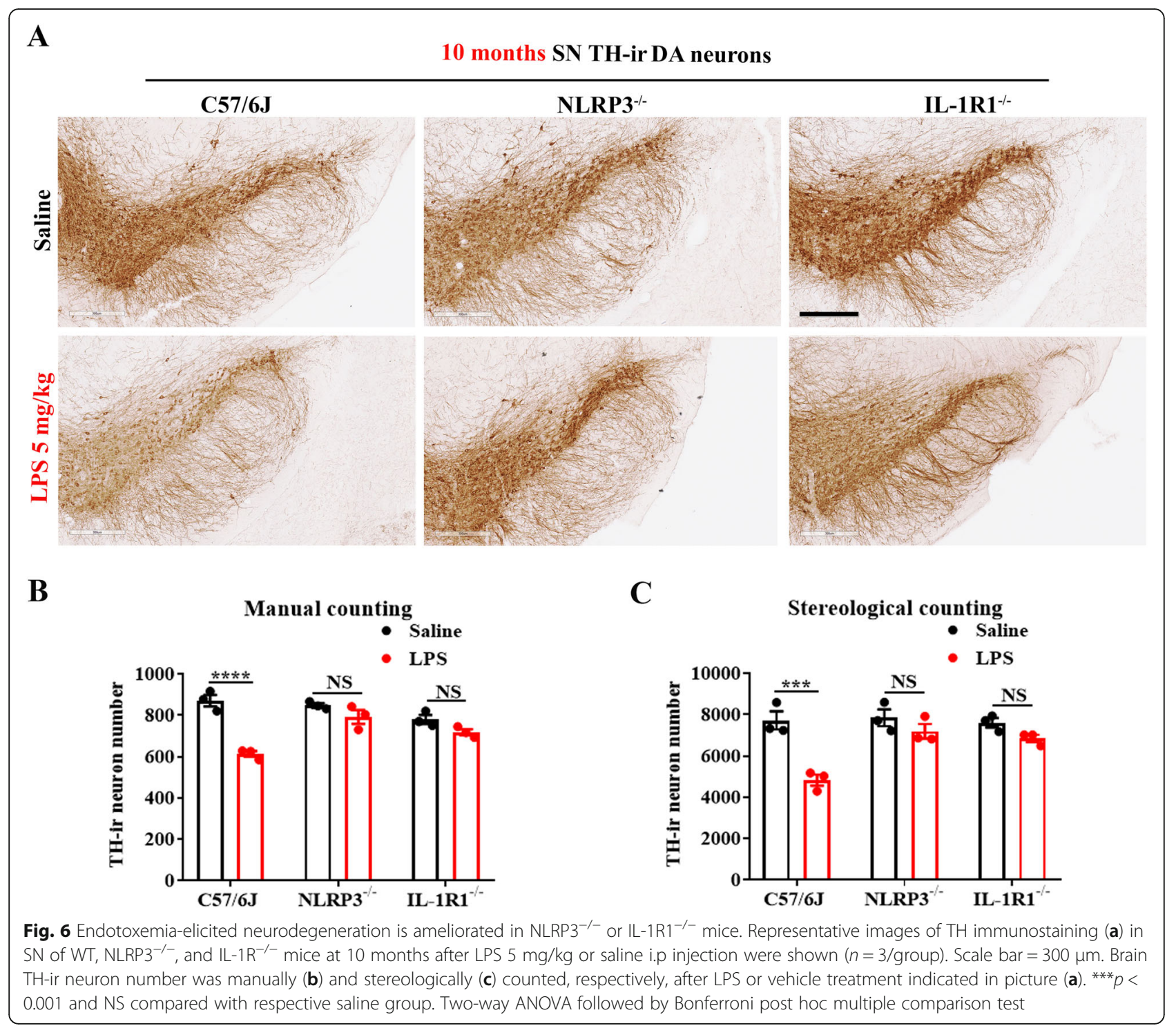

acute neuroinflammation (Fig. 1j). Interestingly, weeks or months after LPS injection, sustained chronic inflammation and neuronal loss were observed only in high doses of LPS-treated mice (Figs. 3 and 6). A unique pattern of brain IL- $1 \beta$ expression led us to believe that this cytokine plays a key role in sustaining high dose LPS-elicited chronic neuroinflammation. Despite no difference in both mRNA and precursor protein levels between high and low doses of LPS, we found that mature IL-1 $\beta$ was the only cytokine displaying a dose-dependent increase in the brain (Fig. 1d-i). As will be discussed below, production of larger amount of brain mature IL- $1 \beta$ is a critical link between higher degree of endotoxemia and chronic neuroinflammation.
Deficiency in NLRP3-IL-1 $\beta$-IL-1R1 does not prevent the initiation of sepsis-associated acute neuroinflammation, but impedes long-term neuroinflammation and neurodegeneration

Production of most cytokines in immune cells is transcriptionally regulated; often translated precursor proteins are fully processed and mature cytokines are released extracellularly. But the production of mature IL-1 $\beta$ is an exception. Processing of precursor proteins to mature IL-1 $\beta$ is tightly regulated by inflammasomes, such as NLRP3 inflammasome; only a portion of the precursor is converted to mature IL-1 $\beta$. This extra regulatory mechanism serves a critical function in gauging the severity of assaults. 


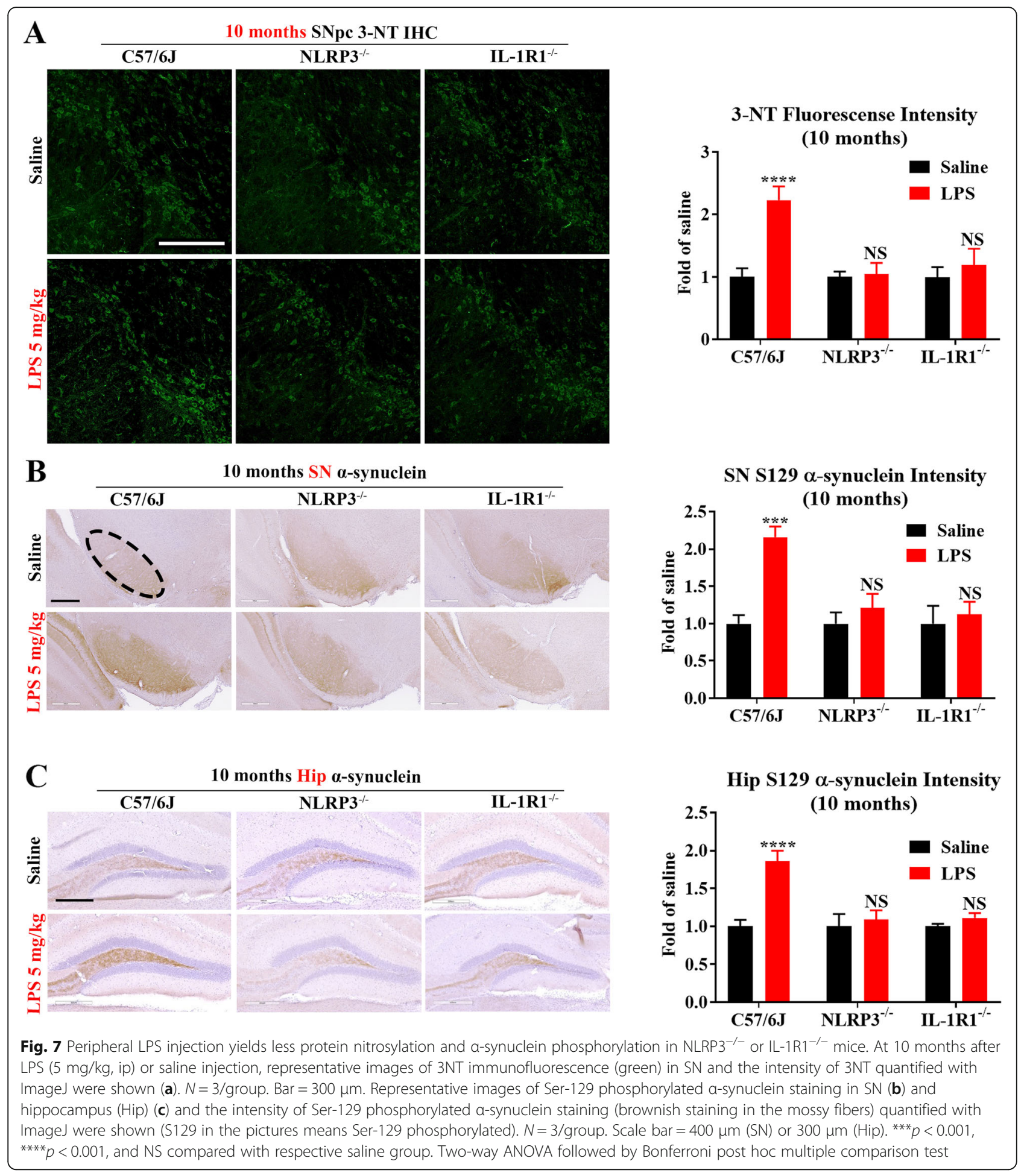

We found that injection of LPS ( $5 \mathrm{mg} / \mathrm{kg}$; i.p.) produced similar increases in the expression of several major brain proinflammatory cytokines, such as TNF $\alpha$, IL-6 (1 h after LPS injection), and microglial activation ( $6 \mathrm{~h}$ after LPS injection) during the acute inflammatory phase in WT and mutant $\left(\mathrm{NLRP3}^{-/-}\right.$, IL-1R1 ${ }^{-/-}$) mice (Fig. 3a and
Additional file 3: Figure S3). By contrast, LPS-induced chronic inflammatory response and progressive neuronal loss in certain brain regions were found in the WT mice, but not in mutant mice (Figs. 3b-d and 6).

Taken together, our findings strongly suggest that the NLRP3-IL-1 $\beta-I L-1 R 1$ signaling does not participate in 


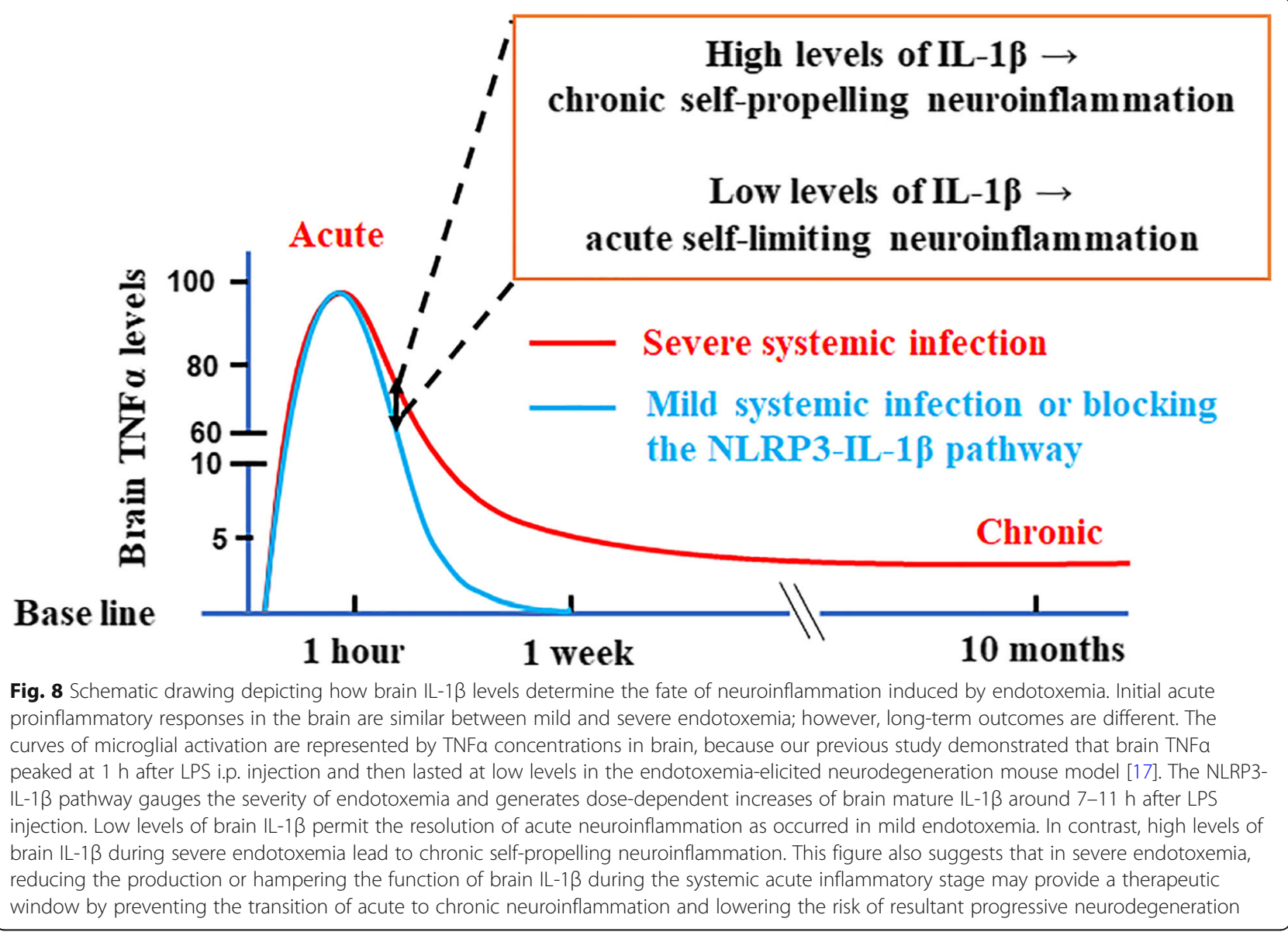

the initiation of acute neuroinflammation, rather the critical role of NLPR3-generated IL-1 $\beta$ is to gate the transition of acute to chronic neuroinflammation.

\section{A permissive role of IL-1 $\beta$ in switching acute self-limiting neuroinflammation to chronic self-propelling neuroinflammation}

As mentioned above, the pathophysiological function of IL-1 $\beta$ during the process of infection-related inflammation in the brain remains unclear. Several observations from this study suggest a permissive role for IL- $1 \beta$ in switching acute self-limiting neuroinflammation to chronic self-propelling neuroinflammation. Although IL$1 \beta$ is considered as a proinflammatory cytokine, our study suggests that it is unlikely that IL-1 $\beta$ directly participates in the formation of acute inflammation. First, blockade of NLRP3-IL-1 $\beta$-IL-1R1 signaling does not prevent the initiation of LPS-induced acute inflammation (Additional file 3: Figure S3 and Fig. 3a). Second, the amount of IL-1 $\beta$ produced by LPS either in cell cultures or in mice brain is several orders of magnitude lower than that of most proinflammatory immune factors, such as TNF $\alpha$, IL-6, MCP-1, etc. Our study showed that adding $80 \mathrm{pg} / \mathrm{ml}$ of recombinant IL- $1 \beta$ alone, which is two times higher than what is measured in vitro, to neuronglial cultures failed to produce neuronal damage. Instead, adding $40 \mathrm{pg} / \mathrm{ml}\left(2.2 \times 10^{-13} \mathrm{M}\right)$ of IL-1 $\beta$ to LPS-treated neuron-glial cultures from NLRP3-deficient mice fully reinstated LPS-induced progressive dopaminergic neuron toxicity (Fig. 5). Third, time course studies showed that the release of IL-1 $\beta$ in LPS-simulated cell cultures was behind the other proinflammatory immune factors and the period of enhanced release of IL-1 $\beta$ was short-lived (Fig. 1). Thus, our study strongly suggests that depending on the severity of challenge, a corresponding amount of IL-1 $\beta$ was strategically released at a critical time point to orchestrate the transition of acute to chronic phase during the process of infection-related inflammation in the brain. Additionally, the permissive role for IL-1 $\beta$ in switching neuroinflammatory phases is supported by the repression of LPS-induced upregulation of late-expressed genes, such as Mac1, NOX2, and MHC-II, in the absence of NLRP3-IL-1 $\beta$ signal (Fig. 4).

Aggregated $\alpha$-synuclein, one of PD hall markers, triggers microglial NLRP3 inflammasome and the downstream effector caspase- 1 to release mature IL-1 $\beta$ [82]. In turn, activated caspase- 1 causes truncation and aggregation of $\alpha$-synuclein [83]. Moreover, inhibition of 
NLRP3 inflammasome was found to prevent $\alpha$-synuclein pathology [84]. It seems that the interplay between aggregated $\alpha$-synuclein and NLRP3 inflammasome is a component of the vicious cycle between damaged neuron and reactivated microglia, which is necessary for maintaining chronic self-propelling neuroinflammation. The finding that $\alpha$-synuclein pathology was greatly diminished in LPS-injected NLRP3 or IL-1R1 KO mice in the present study (Fig. 7) adds further evidence indicating the interaction between $\alpha$-synuclein and NLRP3 inflammasome.

\section{The NLRP3-IL-1 $\beta$-IL-1R1 axis as a potential target for new drug therapy}

Experimental or clinical studies show promising therapeutic results by targeting IL- $1 \beta$ signaling for a broad spectrum of disorders including cardiovascular disease and cancer treatment-associated life-threatening cytokine release syndrome [85-88]. From a clinical viewpoint, our study also provides valuable insights identifying the NLRP3-IL-1 $\beta$-IL-1R1 axis as potential targets for developing new drug therapies for preventing severe infection-elicited chronic inflammation and neurodegeneration. In line with this possibility, MCC950, a small molecule of NLRP3 inflammasome inhibitor, capable of gaining access to the brain, was reported to exert neuronal protective effects in several animal PD models [84]. It is notable that, besides neurotoxicity, IL-1 $\beta$ also plays neuroprotective function under certain experimental conditions. For example, IL-1 $\beta$ was found to participate in both the classical and alternative activation of microglia in a in vivo spinal cord injury mouse model [89]. In vitro, expression of the alternative activation markers arginase-1 and Ym1 was increased in primary microglial cultures after IL- 4 stimulation and further increased after co-treatment with IL- 4 and IL-1 $\beta$. Therefore, cautions must be contextually exercised when considering the application of therapeutic strategies to target IL-1 $\beta$.

Moreover, astroglia can express NLRP3 inflammasome and IL-1 $\beta$ under certain conditions, such as in SOD1 mouse model of amyotrophic lateral sclerosis (ALS) and human sporadic ALS patients, and amyloid $\beta_{1-42}$-stimulated murine astrocytes [90, 91]. We could not rule out the role of astroglia in LPS-induced sepsis-associated neurodegeneration. MCC950 also displayed the potency to repress astroglial NLRP3 inflammasome [91]. These findings highlight the promising application of NLRP3IL-1 $\beta$ signaling inhibition in various neurodegenerative disorders.

\section{Conclusions}

This study uncovers a novel role of the NLRP3-IL-1 $\beta$ signaling pathway in gauging the severity of sepsis- associated inflammation and determining whether acute neuroinflammation will resolve or transition to low grade chronic neuroinflammation. These findings also provide novel targets for developing therapy for severe systemic infection-related neurodegeneration.

\section{Supplementary information}

Supplementary information accompanies this paper at https://doi.org/10. 1186/s12974-020-1728-5.

\begin{abstract}
Additional file 1: Figure S1. Lack of dose-response of LPS-elicited production of $I L-1 \beta$ precursor in the brain. Representative images of western blot analysis of IL-1 $\beta$ precursor in C57BL/6 J mice brain tissue at indicated time after LPS 1 or $5 \mathrm{mg} / \mathrm{kg}$ ip injection. Quantification of the western blot was presented in Fig. 1e.
\end{abstract}

Additional file 2: Figure S2. ER stress mediates LPS-induced processing of microglial precursor to mature IL-1 $\beta$. (a) NLRP3 mRNA was measured by $\mathrm{GPCR}$ at indicated time points in mix-glial cultures after LPS $10^{3} \mathrm{ng} / \mathrm{ml}$ treatment. Results were from 3 independent experiments performed in duplicate. (b) and (c) YVAD, TUDC and $4 \mu 8 C$ were administrated at indicated concentrations in mix-glial cultures at $6 \mathrm{~h}$ after LPS $10^{3} \mathrm{ng} / \mathrm{ml}$ treatment. Culture supernatant levels of $\mathrm{IL}-1 \beta$ were measured at $24 \mathrm{~h}$. Results were from 3 independent experiments. ${ }^{* * *} p<0.0001$ compared to vehicle group and \#p <0.0001 compared to $10^{3} \mathrm{ng} / \mathrm{ml}$ group. One-way ANOVA followed by Bonferroni post hoc multiple comparison test.

Additional file 3: Figure S3. Deficiency in NLRP3 or IL-1R1 does not prevent brain initial acute inflammatory response. At $1 \mathrm{~h}$ after injection of LPS ( $5 \mathrm{mg} / \mathrm{kg}$, ip) or saline vehicle in C57BL/6 J mice, brain mRNA levels of TNFa (a), IL-6 (b), MCP-1 (c), and IL-1 $\beta$ (d) were measured by qPCR ( $n=4$ / group). ${ }^{* * *} p<0.001$ compared with respective saline vehicle group. Twoway ANOVA followed by Bonferroni post hoc multiple comparison test.

Additional file 4: Figure S4. Peripheral LPS injection enhances protein nitrosylation in WT but not mutant mice. Representative images of $\mathrm{TH}$ (red) and 3-NT/TH double (yellow) immunofluorescence double staining

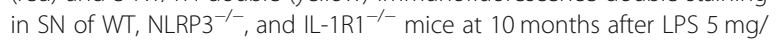
$\mathrm{kg}$ or saline i.p injection ( $n=3 /$ group). Bar $=300 \mu \mathrm{m}$. The 3-NT staining pictures and the quantification of 3-NT intensity were shown in Fig. 7.

\section{Abbreviations}

3-NT: 3-Nitrotyrosine; ER: Endoplasmic reticulum; Iba-1: Ionized calcium binding adaptor molecule 1; IL-1R1: IL-1 receptor 1; IL-1Ra: Interleukin-1

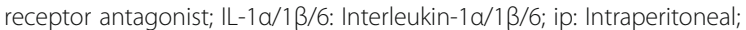
IRE1a: Inositol-requiring enzyme 1a; LPS: Lipopolysaccharide; MCP1: Monocyte chemoattractant protein-1; MHC-II: Major histocompatibility complex II; NLRP3: Nod-like receptor protein 3; NO: Nitric oxide; PD: Parkinson's disease; ROS: Reactive oxygen species; TNFa: Tumor necrosis factor alpha

\section{Acknowledgments}

We thank Drs Shi-Heng Chen and Lu Zhang for technical supports. We thank Drs Hong Li and Shi-Heng Chen for critical reading of the manuscript. We thank the Comparative Medicine Branch (CMB) and the Fluorescence Microscopy and Imaging Center at NIEHS.

\section{Authors' contributions}

$J H, J Y, Y W$, and JF conceived and designed the experiments. ZZ, YW, RZ, YL, WB, and SS performed the experiments and analyzed the data. ZZ, YW, and $J H$ wrote the paper, and JY revised it. YG and DT discussed the data and revised the figures. All authors read and approved the final paper.

\section{Funding}

This research was supported in part through the Intramural Research Program at the National Institute of Environmental Health Sciences in the National Institutes of Health, USA (ZIA ES090082-22); as well as grants from the National Natural Science Foundation of China (81270144, 81570084, 81970083 and 30800507 to J.F.). 


\section{Availability of data and materials}

All data generated or analyzed during this study are included in this article.

\section{Ethics approval and consent to participate}

All the use of the animals in this study has been treated humanely and was performed in strict accordance with the National Institutes of Health guidelines

\section{Consent for publication}

Not applicable.

\section{Competing interests}

The authors declare that they have no competing interests.

\section{Author details}

'Respiratory Department, Tianjin Medical University General Hospital, Tianjin 300052, China. ${ }^{2}$ Neurobiology Laboratory, National Institute of Environmental Health Sciences, National Institutes of Health, Research Triangle Park, NC 27709, USA. ${ }^{3}$ Institute of Infectious Diseases, The Second Hospital of Tianjin Medical University, Tianjin 300211, China.

\section{Received: 5 September 2019 Accepted: 28 January 2020}

\section{Published online: 18 February 2020}

\section{References}

1. Iwashyna TJ, Ely EW, Smith DM, Langa KM. Long-term cognitive impairment and functional disability among survivors of severe sepsis. JAMA. 2010;304: 1787-94.

2. Martyn CN, Osmond C. Parkinson's disease and the environment in early life. J Neurol Sci. 1995:132:201-6.

3. Gilden DH. Infectious causes of multiple sclerosis. Lancet Neurol. 2005;4 195-202.

4. Logroscino $\mathrm{G}$. The role of early life environmental risk factors in Parkinson disease: what is the evidence? Environ Health Perspect. 2005;113:1234-8.

5. Borenstein AR, Copenhaver Cl, Mortimer JA. Early-life risk factors for Alzheimer disease. Alzheimer Dis Assoc Disord. 2006;20:63-72.

6. Jang H, Boltz D, Sturm-Ramirez K, Shepherd KR, Jiao Y, Webster R, et al. Highly pathogenic H5N1 influenza virus can enter the central nervous system and induce neuroinflammation and neurodegeneration. Proc Natl Acad Sci U S A. 2009;106:14063-8.

7. Annane D, Sharshar T. Cognitive decline after sepsis. Lancet Respir Med. 2015;3:61-9.

8. Gao HM, Hong JS. Why neurodegenerative diseases are progressive: uncontrolled inflammation drives disease progression. Trends Immunol. 2008;29:357-65

9. Frank-Cannon TC, Alto LT, McAlpine FE, Tansey MG. Does neuroinflammation fan the flame in neurodegenerative diseases? Mol Neurodegener. 2009:4:47.

10. Glass CK, Saijo K, Winner B, Marchetto MC, Gage FH. Mechanisms underlying inflammation in neurodegeneration. Cell. 2010;140:918-34.

11. Gao HM, Zhou H, Zhang F, Wilson BC, Kam W, Hong JS. HMGB1 acts on microglia Mac1 to mediate chronic neuroinflammation that drives progressive neurodegeneration. J Neurosci. 2011;31:1081-92.

12. Gonzalez H, Elgueta D, Montoya A, Pacheco R. Neuroimmune regulation of microglial activity involved in neuroinflammation and neurodegenerative diseases. J Neuroimmunol. 2014;274:1-13.

13. Kempuraj D, Thangavel R, Natteru PA, Selvakumar GP, Saeed D, Zahoor H, et al. Neuroinflammation Induces Neurodegeneration. J Neurol Neurosurg Spine. 2016:1:1.

14. Ransohoff RM. How neuroinflammation contributes to neurodegeneration. Science. 2016:353:777-83.

15. Joers V, Tansey MG, Mulas G, Carta AR. Microglial phenotypes in Parkinson's disease and animal models of the disease. Prog Neurobiol. 2017:155:57-75.

16. Hickman S, Izzy S, Sen P, Morsett L, El Khoury J. Microglia in neurodegeneration. Nat Neurosci. 2018;21:1359-69.

17. Qin L, Wu X, Block ML, Liu Y, Breese GR, Hong JS, et al. Systemic LPS causes chronic neuroinflammation and progressive neurodegeneration. Glia. 2007:55:453-62.

18. Liu Y, Qin L, Wilson B, Wu X, Qian L, Granholm AC, et al. Endotoxin induces a delayed loss of TH-IR neurons in substantia nigra and motor behavioral deficits. Neurotoxicology. 2008;29:864-70.
19. Qin L, Liu Y, Hong JS, Crews FT. NADPH oxidase and aging drive microglial activation, oxidative stress, and dopaminergic neurodegeneration following systemic LPS administration. Glia. 2013;61:855-68.

20. Hoban DB, Connaughton E, Connaughton C, Hogan G, Thornton C, Mulcahy $P$, et al. Further characterisation of the LPS model of Parkinson's disease: a comparison of intra-nigral and intra-striatal lipopolysaccharide administration on motor function, microgliosis and nigrostriatal neurodegeneration in the rat. Brain Behav Immun. 2013;27:91-100.

21. Wang Q, Qian L, Chen SH, Chu CH, Wilson B, Oyarzabal E, et al. Posttreatment with an ultra-low dose of NADPH oxidase inhibitor diphenyleneiodonium attenuates disease progression in multiple Parkinson's disease models. Brain. 2015;138:1247-62.

22. Song S, Jiang L, Oyarzabal EA, Wilson B, Li Z, Shih Yl, et al. Loss of brain norepinephrine elicits neuroinflammation-mediated oxidative injury and selective caudo-rostral neurodegeneration. Mol Neurobiol. 2019;56:2653-69.

23. Song S, Wang Q, Jiang L, Oyarzabal E, Riddick NV, Wilson B, et al. Noradrenergic dysfunction accelerates LPS-elicited inflammation-related ascending sequential neurodegeneration and deficits in non-motor/motor functions. Brain Behav Immun. 2019;81:374-87.

24. Sonneville R, Verdonk F, Rauturier C, Klein IF, Wolff M, Annane D, et al. Understanding brain dysfunction in sepsis. Ann Intensive Care. 2013:3:15.

25. Sims JE, Smith DE. The IL-1 family: regulators of immunity. Nat Rev Immunol. 2010;10:89-102.

26. Miller LS, O'Connell RM, Gutierrez MA, Pietras EM, Shahangian A, Gross CE, et al. MyD88 mediates neutrophil recruitment initiated by IL-1R but not TLR2 activation in immunity against Staphylococcus aureus. Immunity. 2006:24:79-91.

27. Gasse P, Mary C, Guenon I, Noulin N, Charron S, Schnyder-Candrian S, et al. L-1R1/MyD88 signaling and the inflammasome are essential in pulmonary inflammation and fibrosis in mice. J Clin Invest. 2007;117:3786-99.

28. Bergsbaken T, Fink SL, Cookson BT. Pyroptosis: host cell death and inflammation. Nat Rev Microbiol. 2009;7:99-109.

29. Garlanda C, Dinarello CA, Mantovani A. The interleukin-1 family: back to the future. Immunity. 2013;39:1003-18.

30. Cullen SP, Kearney CJ, Clancy DM, Martin SJ. Diverse activators of the NLRP3 inflammasome promote IL-1 beta secretion by triggering necrosis. Cell Rep. 2015:11:1535-48.

31. Martin SJ. Cell death and inflammation: the case for IL-1 family cytokines as the canonical DAMPs of the immune system. FEBS J. 2016;283:2599-615.

32. Mayer-Barber KD, Yan B. Clash of the cytokine titans: counter-regulation of interleukin-1 and type I interferon-mediated inflammatory responses. Cell Mol Immunol. 2017:14:22-35.

33. Lamkanfi M, Dixit VM. Mechanisms and functions of inflammasomes. Cell. 2014:157:1013-22

34. Rathinam VA, Fitzgerald KA. Inflammasome complexes: emerging mechanisms and effector functions. Cell. 2016;165:792-800.

35. Broz P, Dixit VM. Inflammasomes: mechanism of assembly, regulation and signalling. Nat Rev Immunol. 2016:16:407-20.

36. He Y, Hara H, Nunez G. Mechanism and regulation of NLRP3 Inflammasome activation. Trends Biochem Sci. 2016:41:1012-21.

37. Chen J, Chen ZJ. Ptdlns4P on dispersed trans-Golgi network mediates NLRP3 inflammasome activation. Nature. 2018:564:71-6.

38. von Bernhardi R, Eugenin-von Bernhardi L, Eugenin J. Microglial cell dysregulation in brain aging and neurodegeneration. Front Aging Neurosci. 2015:7:124

39. Gustin A, Kirchmeyer M, Koncina E, Felten P, Losciuto S, Heurtaux T, et al. NLRP3 inflammasome is expressed and functional in mouse brain microglia but not in astrocytes. PLoS One. 2015;10:e0130624.

40. Abderrazak A, Syrovets T, Couchie D, El Hadri K, Friguet B, Simmet T, et al. NLRP3 inflammasome: from a danger signal sensor to a regulatory node of oxidative stress and inflammatory diseases. Redox Biol. 2015:4:296-307.

41. Weber MD, Frank MG, Tracey KJ, Watkins LR, Maier SF. Stress induces the danger-associated molecular pattern HMGB-1 in the hippocampus of male Sprague Dawley rats: a priming stimulus of microglia and the NLRP3 inflammasome. J Neurosci. 2015;35:316-24.

42. Xu C, Bailly-Maitre B, Reed JC. Endoplasmic reticulum stress: cell life and death decisions. J Clin Invest. 2005;115:2656-64.

43. Bronner DN, Abuaita BH, Chen X, Fitzgerald KA, Nunez G, He Y, et al. Endoplasmic reticulum stress activates the inflammasome via NLRP3- and caspase-2-driven mitochondrial damage. Immunity. 2015:43:451-62.

44. Mao Z, Liu C, Ji S, Yang Q, Ye H, Han H, et al. The NLRP3 Inflammasome is involved in the pathogenesis of Parkinson's disease in rats. Neurochem Res. 2017;42:1104-15. 
45. Sarkar S, Malovic E, Harishchandra DS, Ghaisas S, Panicker N, Charli A, et al. Mitochondrial impairment in microglia amplifies NLRP3 inflammasome proinflammatory signaling in cell culture and animal models of Parkinson's disease. NPJ Parkinsons Dis. 2017;3:30

46. Qian L, Wu HM, Chen SH, Zhang D, Ali SF, Peterson L, et al. beta2adrenergic receptor activation prevents rodent dopaminergic neurotoxicity by inhibiting microglia via a novel signaling pathway. J Immunol. 2011;186:4443-54.

47. Chen SH, Oyarzabal EA, Sung YF, Chu CH, Wang Q, Chen SL, et al. Microglial regulation of immunological and neuroprotective functions of astroglia. Glia. 2015;63:118-31.

48. Quan N, Whiteside M, Herkenham M. Time course and localization patterns of interleukin-1beta messenger RNA expression in brain and pituitary after peripheral administration of lipopolysaccharide. Neuroscience. 1998;83:281-93.

49. Tyrtyshnaia AA, Lysenko LV, Madamba F, Manzhulo IV, Khotimchenko MY, Kleschevnikov AM. Acute neuroinflammation provokes intracellular acidification in mouse hippocampus. J Neuroinflammation. 2016;13:283.

50. Wendeln AC, Degenhardt K, Kaurani L, Gertig M, Ulas T, Jain G, et al. Innate immune memory in the brain shapes neurological disease hallmarks. Nature. 2018;556:332-8.

51. Hao C, Guilbert LJ, Fedoroff S. Production of colony-stimulating factor-1 (CSF-1) by mouse astroglia in vitro. J Neurosci Res. 1990;27:314-23.

52. Hu X, Zhang D, Pang H, Caudle WM, Li Y, Gao H, et al. Macrophage antigen complex-1 mediates reactive microgliosis and progressive dopaminergic neurodegeneration in the MPTP model of Parkinson's disease. J Immunol. 2008;181:7194-204.

53. Zhang $Y$, Liu L, Peng $Y L$, Liu $Y Z$, Wu TY, Shen $X L$, et al. Involvement of inflammasome activation in lipopolysaccharide-induced mice depressive-like behaviors. CNS Neurosci Ther. 2014;20:119-24.

54. Jeon SA, Lee E, Hwang I, Han B, Park S, Son S, et al. NLRP3 Inflammasome contributes to lipopolysaccharide-induced depressive-like behaviors via Indoleamine 2,3-dioxygenase induction. Int J Neuropsychopharmacol. 2017:20:896-906.

55. Zhu W, Cao FS, Feng J, Chen HW, Wan JR, Lu Q, et al. NLRP3 inflammasome activation contributes to long-term behavioral alterations in mice injected with lipopolysaccharide. Neuroscience. 2017;343:77-84.

56. Coll RC, Robertson AA, Chae JJ, Higgins SC, Munoz-Planillo R, Inserra MC, et al. A small-molecule inhibitor of the NLRP3 inflammasome for the treatment of inflammatory diseases. Nat Med. 2015;21:248-55.

57. Jangra A, Sriram CS, Lahkar M. Lipopolysaccharide-induced behavioral alterations are alleviated by sodium Phenylbutyrate via attenuation of oxidative stress and neuroinflammatory cascade. Inflammation. 2016;39: $1441-52$.

58. Zhang W, Dallas S, Zhang D, Guo JP, Pang H, Wilson B, et al. Microglial $\mathrm{PHOX}$ and mac-1 are essential to the enhanced dopaminergic neurodegeneration elicited by A30P and A53T mutant alpha-synuclein. Glia. 2007:55:1178-88.

59. Zhang D, Hu X, Qian L, Chen SH, Zhou H, Wilson B, et al. Microglial MAC1 receptor and PI3K are essential in mediating beta-amyloid peptide-induced microglial activation and subsequent neurotoxicity. J Neuroinflammation. 2011;8:3.

60. Harms AS, Cao S, Rowse AL, Thome AD, Li X, Mangieri LR, et al. MHCll is required for alpha-synuclein-induced activation of microglia, CD4 T cell proliferation, and dopaminergic neurodegeneration. J Neurosci. 2013;33: 9592-600.

61. Chen SH, Oyarzabal EA, Hong JS. Critical role of the Mac1/NOX2 pathway in mediating reactive microgliosis-generated chronic neuroinflammation and progressive neurodegeneration. Curr Opin Pharmacol. 2016;26:54-60.

62. Hong S, Beja-Glasser VF, Nfonoyim BM, Frouin A, Li S, Ramakrishnan S, et al. Complement and microglia mediate early synapse loss in Alzheimer mouse models. Science. 2016;352:712-6.

63. Czirr E, Castello NA, Mosher Kl, Castellano JM, Hinkson IV, Lucin KM, et al. Microglial complement receptor 3 regulates brain Abeta levels through secreted proteolytic activity. J Exp Med. 2017;214:1081-92.

64. Sulzer D, Alcalay RN, Garretti F, Cote L, Kanter E, Agin-Liebes J, et al. T cells from patients with Parkinson's disease recognize alpha-synuclein peptides. Nature. 2017;546:656-61.

65. Hopperton KE, Mohammad D, Trepanier MO, Giuliano V, Bazinet RP. Markers of microglia in post-mortem brain samples from patients with Alzheimer's disease: a systematic review. Mol Psychiatry. 2018;23:177-98.
66. Lecours C, Bordeleau M, Cantin L, Parent M, Paolo TD, Tremblay ME. Microglial implication in Parkinson's disease: loss of beneficial physiological roles or gain of inflammatory functions? Front Cell Neurosci. 2018;12:282.

67. Williams GP, Schonhoff AM, Jurkuvenaite A, Thome AD, Standaert DG, Harms AS. Targeting of the class II transactivator attenuates inflammation and neurodegeneration in an alpha-synuclein model of Parkinson's disease. J Neuroinflammation. 2018;15:244.

68. Nakamura T, Lipton SA. Redox modulation by S-nitrosylation contributes to protein misfolding, mitochondrial dynamics, and neuronal synaptic damage in neurodegenerative diseases. Cell Death Differ. 2011;18:1478-86.

69. Nakamura T, Tu S, Akhtar MW, Sunico CR, Okamoto S, Lipton SA. Aberrant protein s-nitrosylation in neurodegenerative diseases. Neuron. 2013;78:596-614.

70. Oueslati A. Implication of alpha-synuclein phosphorylation at S129 in Synucleinopathies: what have we learned in the last decade? J Park Dis. 2016;6:39-51.

71. Henchcliffe C, Beal MF. Mitochondrial biology and oxidative stress in Parkinson disease pathogenesis. Nat Clin Pract Neurol. 2008;4:600-9.

72. Ozansoy M, Basak AN. The central theme of Parkinson's disease: alphasynuclein. Mol Neurobiol. 2013:47:460-5.

73. Blesa J, Trigo-Damas I, Quiroga-Varela A, Jackson-Lewis VR. Oxidative stress and Parkinson's disease. Front Neuroanat. 2015;9:91.

74. Si X, Pu J, Zhang B. Structure, distribution, and genetic profile of alphasynuclein and their potential clinical application in Parkinson's disease. J Mov Disord. 2017;10:69-79.

75. Hoogland IC, Houbolt C, van Westerloo DJ, van Gool WA, van de Beek D. Systemic inflammation and microglial activation: systematic review of animal experiments. J Neuroinflammation. 2015;12:114.

76. Kozak W, Kluger MJ, Soszynski D, Conn CA, Rudolph K, Leon LR, et al. IL-6 and IL-1 beta in fever. Studies using cytokine-deficient (knockout) mice. Ann N Y Acad Sci. 1998:856:33-47.

77. Dantzer R. Cytokine, sickness behavior, and depression. Immunol Allergy Clin N Am. 2009;29:247-64.

78. Granger JI, Ratti PL, Datta SC, Raymond RM, Opp MR. Sepsis-induced morbidity in mice: effects on body temperature, body weight, cage activity, social behavior and cytokines in brain. Psychoneuroendocrinology. 2013;38:1047-57.

79. Rao S, Schieber AMP, O'Connor CP, Leblanc M, Michel D, Ayres JS. Pathogen-mediated inhibition of anorexia promotes host survival and transmission. Cell. 2017;168:503-16. e512

80. Gayle DA, Ling Z, Tong C, Landers T, Lipton JW, Carvey PM. Lipopolysaccharide (LPS)-induced dopamine cell loss in culture: roles of tumor necrosis factor-alpha, interleukin-1beta, and nitric oxide. Brain Res Dev Brain Res. 2002;133:27-35.

81. Ferrari CC, Pott Godoy MC, Tarelli R, Chertoff M, Depino AM, Pitossi FJ. Progressive neurodegeneration and motor disabilities induced by chronic expression of IL-1beta in the substantia nigra. Neurobiol Dis. 2006;24:183-93.

82. Codolo G, Plotegher N, Pozzobon T, Brucale M, Tessari I, Bubacco L, et al. Triggering of inflammasome by aggregated alpha-synuclein, an inflammatory response in synucleinopathies. PLoS One. 2013;8:e55375.

83. Wang W, Nguyen LT, Burlak C, Chegini F, Guo F, Chataway T, et al. Caspase1 causes truncation and aggregation of the Parkinson's disease-associated protein alpha-synuclein. Proc Natl Acad Sci U S A. 2016;113:9587-92.

84. Gordon R, Albornoz EA, Christie DC, Langley MR, Kumar V, Mantovani S, et al. Inflammasome inhibition prevents alpha-synuclein pathology and dopaminergic neurodegeneration in mice. Sci Transl Med. 2018;10:465.

85. Dinarello CA, Simon A, van der Meer JW. Treating inflammation by blocking interleukin-1 in a broad spectrum of diseases. Nat Rev Drug Discov. 2012;11:633-52.

86. Ridker PM, Everett BM, Thuren T, MacFadyen JG, Chang WH, Ballantyne C, et al. Antiinflammatory therapy with Canakinumab for atherosclerotic disease. N Engl J Med. 2017;377:1119-31.

87. Giavridis T, van der Stegen SJC, Eyquem J, Hamieh M, Piersigilli A, Sadelain M. CAR T cell-induced cytokine release syndrome is mediated by macrophages and abated by IL-1 blockade. Nat Med. 2018;24:731-8.

88. Norelli M, Camisa B, Barbiera G, Falcone L, Purevdorj A, Genua M, et al. Monocyte-derived IL-1 and IL-6 are differentially required for cytokine-release syndrome and neurotoxicity due to CAR T cells. Nat Med. 2018;24:739-48.

89. Sato A, Ohtaki H, Tsumuraya T, Song D, Ohara K, Asano M, et al. Interleukin1 participates in the classical and alternative activation of microglia/ macrophages after spinal cord injury. J Neuroinflammation. 2012;9:65. 
90. Johann S, Heitzer M, Kanagaratnam M, Goswami A, Rizo T, Weis J, et al. NLRP3 inflammasome is expressed by astrocytes in the SOD1 mouse model of ALS and in human sporadic ALS patients. Glia. 2015;63:2260-73.

91. Ebrahimi T, Rust M, Kaiser SN, Slowik A, Beyer C, Koczulla AR, et al. alpha1antitrypsin mitigates NLRP3-inflammasome activation in amyloid beta1-42stimulated murine astrocytes. J Neuroinflammation. 2018;15:282.

\section{Publisher's Note}

Springer Nature remains neutral with regard to jurisdictional claims in published maps and institutional affiliations.

Ready to submit your research? Choose BMC and benefit from:

- fast, convenient online submission

- thorough peer review by experienced researchers in your field

- rapid publication on acceptance

- support for research data, including large and complex data types

- gold Open Access which fosters wider collaboration and increased citations

- maximum visibility for your research: over $100 \mathrm{M}$ website views per year

At BMC, research is always in progress.

Learn more biomedcentral.com/submissions 